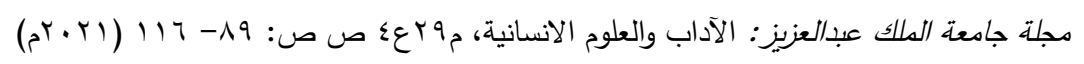

DOI:10.4197/Art.29-4.4

\title{
الخطاب التلميحي في تداولية البيت الشعري عند ابن رجب الحنبلي كتاب جامع العلوم والحكم أنموذجًا
}

\author{
د. عوض بن إبراهيم بن خليف العنزي

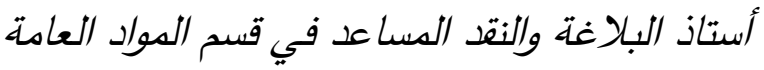 \\ كلية العلوم والآداب- جامعة الحدود الثمالية
}

مستخلص. تبرز أهمية البيت الثعري عندما يوظَّف في غير مظانه ومن تلك الهظان كتب شرح الحديث النبوي؛ إذ يأتي توظيفها من أجل خدمة النص النبوي، وتمكّين معانيه عند المتلقيّن.

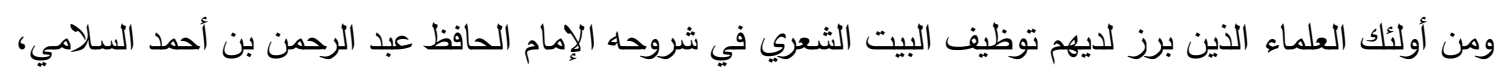

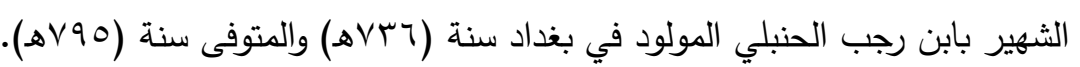

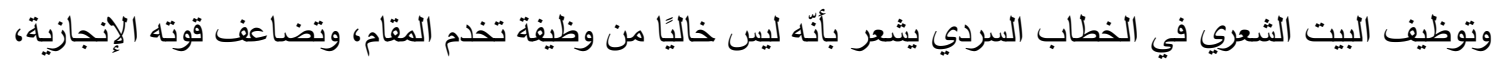
وتكشف عن تلميحات المرسل في توظيفه التي يكون فيها متّددًا مع المرسل إليه. ولطبيعة المادة العلمية الشعرية المجموعة انقسم البحث على: مقدمة ومبحثين وخاتمة، وألحقت بها ثبتًا بالمراجع التي أسهمت في التكوين والإثراء. الكلمات المفتاحية: التداولية، الإثاريات، التوظيف، إستراتيجيات الخطاب.

المتلقي، وينجز بالبيت الشعري ما لا يمكن أنْ ينجزه

\section{المقدمة}

تتضاعف أهمية البيت الشعري عندما يوظف في بالخطاب السردي. ومن تلك الخطابات الشارحة للحديث النبوي خطاب الخطابات السردية التي تقارب الحقيقة العلمية أكثر لفرئ ابن رجب الحنبلي في كتابه: جامع العلوم والحكم في من الخيال، ولذلك لا يمكن أنْ يكون وجودها متداخلة

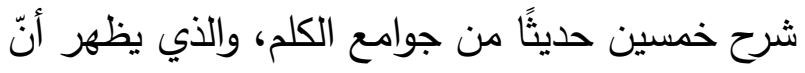
مع النثر إلا لسبب جوهريّ يبتغيه منشئ الخطاب؛ ليضاعف أثر خطابه، ويزيد في تمكينه من ذهن المؤلّف أراد أنْ يكون كتابَه جامعًا بين العلم والحكمة 
وتصف المعاجم اللغوية الخطاب بأنه مواجهة بين طرفين يتوسطها الكلام، ولابد أنْ يكون فيه غايةٌ نفعيّة يطلبها المرسل لتحصل له كخطبة المرأة أو تحصل في غيره كالخطبة أمام الناس(؟)، وأشار الخليل بن أحمد الفراهيدي في تعريفه للخطاب بأنه مراجعة الكلام، وهذه المراجعة تعني أنّ بين الطرفين تواصلا تبادليًّا فالمرسل خطابه ملفوظ والمرسل إليه خطابه مفهوم لكنه لا يكون استجابةً إلا عندما يحصل المضمر عند المرسل في المرسل إليه(r) . واتصلت كلمة الخطاب بالبيان فقولك: "أنت الأخطب البيّن الخطبة فتخيّل إليه أنه ذو البيان في خطبته"(汭هذا يشير إلى أنّ الخطاب مفهوم عام يطلق على ما كان البيان غايته، وليس المقصود بالبيان الظهور والوضوح، بل البيان هو التفنّن في الكلام؛ بدليل أنه جعله مقيدًا بقوله: (في خطبته)، والخطبة جنس أدبي بياني يقتضي لغةً روعي فيها ما يُهَيّأ به الكلام من الفنون القولية والبيانية. وردت كلمة (الخطاب) في القرآن الكريم في قوله تعالى: (وآتيناه الحكمة وفصل الخطاب)، وفي تفسيرها رأيان يمكن إدخال الأول منهما في الثاني؛ فأول الرأيين ما قاله الزمخشري (تمیrهـ) بأنّ المقصود بفصل الخطاب هو "الكلام المبيّن الدال على المقصود بلا

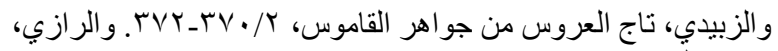

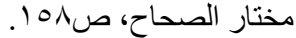

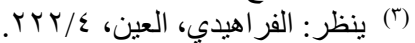

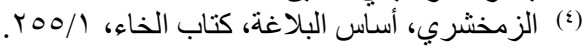

من خلال استحضار (إنّ من الثعر لحكمة) وتجاورها

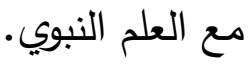
وقد كان المنهج التداولي من أنسب المناهج في مقاربة التداخل بين الشعر والنثر في الخطاب الشارح للحديث النبوي؛ لما يوفّره من مداخل متعددة تساعد على قراءة طرائق التوظيف، واكتشاف التلميحات للمضدر، والإشاريات، ومعرفة الإستراتيجية الخطابية التي سلكها الخطاب. وقد اقتضت طبيعة البحث أنْ يقسم إلى مقدمة وثلاثة مباحث: الأول منها عنوانه مفهوم الخطاب التلميحي، والثاني في طرائق التوظيف التداولي للبيت الشعري، والثالث تحدثت فيه عن البعد الإشاري لتداولية البيت الشعري، ثم ذكرت في الخاتمة نتائج البحث، ثم مسرد المراجع. المبحث الأول: مفهوم الخطاب التلميحي. أ- - أخطاب: - أن إن يعدّ الحديث عن الخطاب حديثًا عن عنصر يساعد على بناء التصور الأمثل لطبيعة التواصل البشري(')، وفهم طبيعة الحياة التي عاشها المرسل وانتقلت آثارها من خلال مقاصده التي أودعها في خطابه الذي وصلنا، وكشف مناشئ الخطاب التي تكوّن الخطاب حاملا صفاتها المعيارية أو صفاتها النفسية أو غاياتها القيمية والأخلاقية. 
ومن خلال كلام الرازي يظهر للباحث أنّ مفهوم الخطاب يحمل أمرين: الأول منهما المطلوب بالخطاب، والآخر المرغوب فيه، فكل خطاب توجد فيه دلالة المطلوبات التي يريد المرسل والمرسل إليه الوصول إليها من خلال التواصل، وتوجد فيه دلالة المرغوبات التي هي هدف المتلقي الذي هو أحد طرفي العملية التواصلية أو ذلك الضمنيّ المصنوع من أجله الخطاب؛ لأن المتلقي الباحث عن المعرفة يتوجّه إلى تلك الخطابات الثريّة التي يتوقّع أنّ فيها مطلوبه ومرغوبه على السواء، ولذلك تحظى الخطابات التي تفسر النصوص المقدّسة باحترام فكري عند الباحثين لما تقدمه من مطلوبات، وما تثريه فيهم من مرغوبات معرفية تتجاوز الدلالة المباشرة في الخطاب. أما الخطاب في الدراسات التداولية فإنّه يمكن النظر إليه من ناحية تأثيره فيكون ملفوظًا موجّها إلى الآخر بقصد التأثير، ويكون من جهة الصياغة التعبيرية شكلا لغويًّا تتجاوز فيه جملته التي هي أصغر وحداته معناه الحرفي إلى آفاق أخرى غير مباشرة، ويأتي من جهة السياق بوصفه فضاء لمواقع وأنشطة متباينة للذوات(Y).وتفسير الخطاب بأنه استعمال للعلامات الصوتية والمكتوبة من أجل التبليغ عن رغباتهم بله

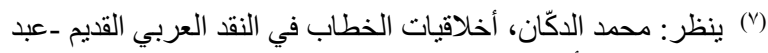

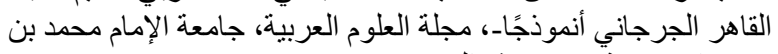

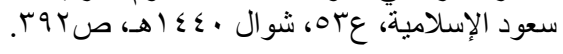

التباس"(0)، ويفهم من قوله أنّ الخطاب ذو معنى محدّد لا يتعدد ولا يتناسل.

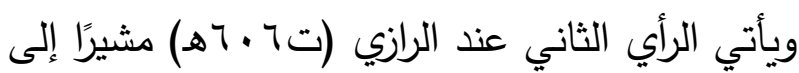

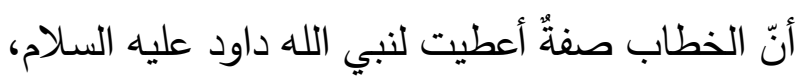
وهو علامة لتمييز الإنسان عن سائر المخلوقات بما اجتمع فيه من قدرتي الإدراك والثعور • وقسّم الرازيّ الناس في القدرة على التعبير التي هي التردي من خلال عبارته مؤشرُ لمقدار القوة الإدراكية والشعورية، وجعلهم أحد إنسانين: إنسان متعذر عليه الترتيب لعبارته عمّا نشأ في ضميره، والآخر إنسان إندان قادر على ضبط المعنى الناشئ في الضمير ، والتعبير عنه إلى أقصى الغايات، وهو معنى يضمُّ أفرادًا كثيرين بسبب تفاوت الناس في القدرة على التعبير •

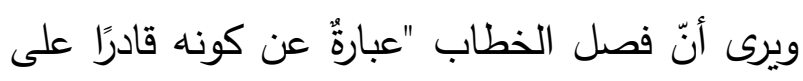
التعبير عن كل ما يخطر بالبال، ويحضر في الخيال،

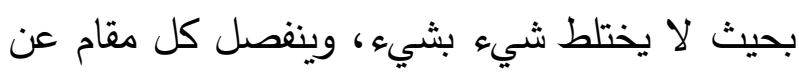

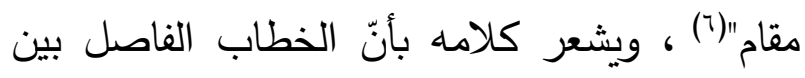
الناس موجود على تفاوت أقدارهم في القوة الإدراكية والثعورية، وهو أحد المصادر المعرفيّة المرجعيّة للثقافة عندما يُعتنى به؛ لأنه يتحقق فيه عند العناية

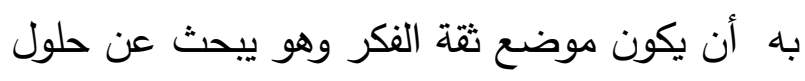

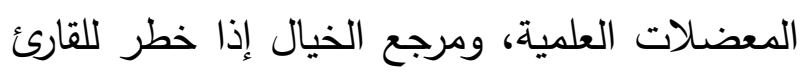

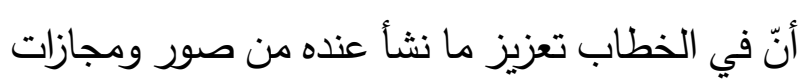
في اللغة. 
لغوية وغير لغوية، وبذلك يصبح الخطاب بؤرةً مكثّفة

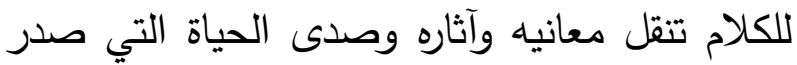

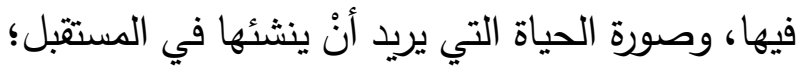
لأنه شبكة معقّة من النظم الاجتماعية والسياسية والثقافية التي تبرز فيها الكيفية التي ينتج فيها الكلام حاملا صفة الخطاب(10) مابل وفي هذا الاتجاه السياقي يأتي الخطاب عبارة عن مجموعة من العبارات التي تتنسب إلى نظام لتهام تكوّنها(1')، وهذا ما يفسّر تتوعه بين خطاب ينطلق من سياقه المعرفي كالتاريخي والتقسيري، أو ينطلق من غاية صاحبه كالخطاب التلميحي والتوجيهي والإقتاعي، أو ينطلق من واقع متلقيه كالخطاب

$$
\text { الاجتماعي والأخلاقي. }
$$

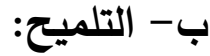

يدور معنى التلميح في المعاجم حول اختلاس النظر

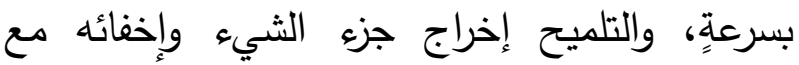
السرعة، وتطلق اللمحة على النظرة السريعة، ويشير إحرة جلير

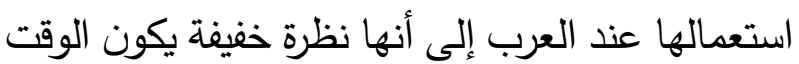

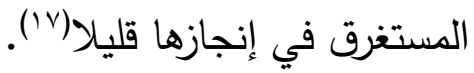
واللمحة أو التلميح عند العرب لا يكون إلا من بعيد،

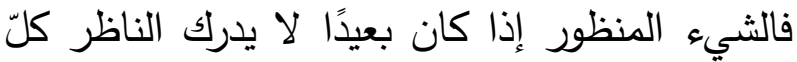

(') ينظر: نعمان بوقرة، لسانيات الخطاب مباحث في الثأسيس والإجراء، صوبا. (10) ينظر : دليل الناقد الأدبي، ميجان الرويلي وسعد الباز عي، صـیـــ

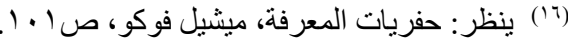

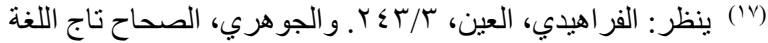

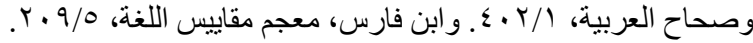
و الزبيدي، تاج العروس من جواهر القاموس، ل/ . . . ـ والرازي، مختار
أوآرائهم(^) يدل على أنّ الخطاب -وإِنْ كان لغةًَ- لا

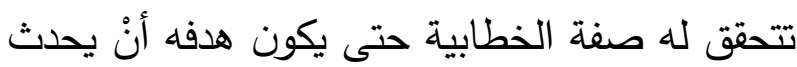
أثثرًا في الآخرين(9)، والخطاب يحمل دلالات ملفوظة في الكلام ودلالات أخرى غير ملفوظة يدركها

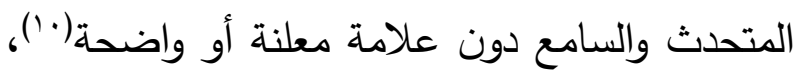
"وبالرغم من أنّ الخطاب يتوسل دائما اللغة في غاياته فإنّ جوهره في حقيقة الأمر ليس لغويًا إذ هو مجموعة الب لئل من النوايا التي تتحقق بوساطة اللغة"(')

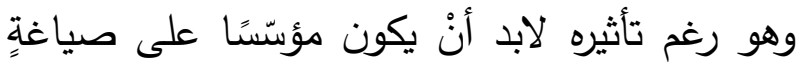
تعبيرية تكون جسرًا لتبادل المقاصد التداولية بعد تفهّم

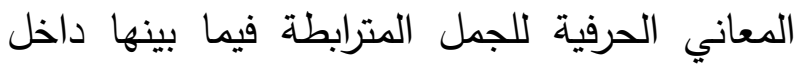
المقصد العام للخطاب، وكأنّا في الخطاب نقول بأنّه لغة كامنة وراء الجمل(rا) التي هي عبارة عن وحدات لسانية روعي فيها الانسجام والتماسك لتكون خطابًا(ז')، وهو كل ملفوظ أكبر من الجملة منظورًا إليه من حيث قواعد التسلسل الجملي(ء () . ويلحظ أصحاب الاتجاه الثالث في الخطاب صورته الحضاريّة فيرون أنّ له أبعادًا وحدودًا إضافية، وأنه الهاه عبارة عن مدى جديد للكلام ينتج لغة من خلال اللغة

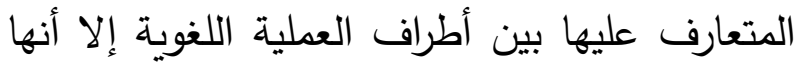

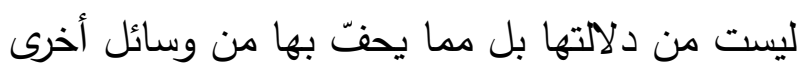

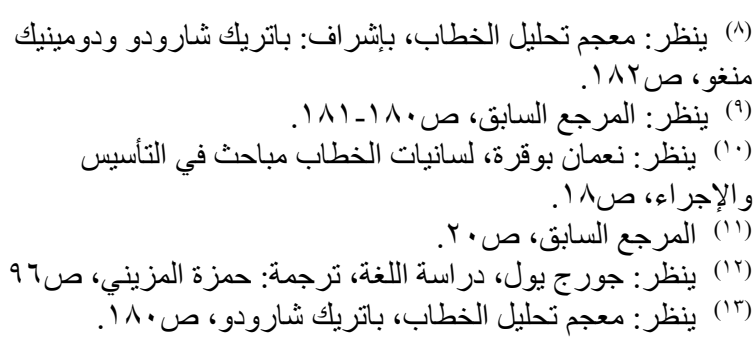


لمحة هو إشارةٌ إلى شيء وفق مستوى عبروا عنه باختلاف المصطلحات التي ضموها إلى باب الإشارة. والإشارة باب كبير من أبواب البلاغة ذكر فيه ابن رشيق القيرواني: الوحي، وما هو على معنى التشبيه، والتفخيم، والإيماء، والتعريض، والتلويح، والكناية،

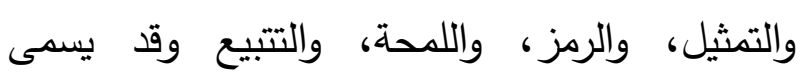
التجاوز ، واللغز، واللحن، والمحاجاة، والتعمية، واستعمال الأصوات في الثعر دون الكلمات، والحذف، والتورية (rr).

وأقرب ما وجدته إلى معنى التلميح ما أطلق عليه ابن رشيق اللحن وهو كلام يعرفه المخاطب بفحواه وإن كان على غير وجهه... وقال أنّ الناس في وقته

يسمونه المحاجاة لدلالة الحجا عليه، وذكر منه:

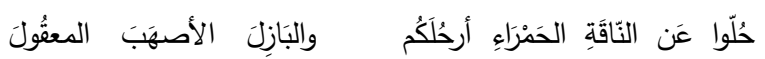

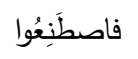

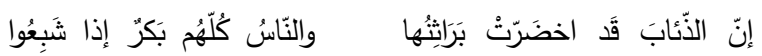

أراد بالناقة الحمراء الدهناء، وبالجمل الأصهب الصمّان، وبالذئاب الأعداء، يقول: قد اخضرت أقدامهم من المشي في الكلأ والخصب والناس كلهم إذا شبعوا طلبوا الغزو فصاروا أعداء لكم كما أنّ بكر

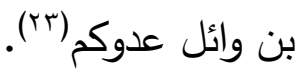
وهذا الاتجاه عند البلاغيين يدلّ على أنّ التلميح هو الإشارة عنهم، وهو متفاوت الدرجات مثل تفاوت

للخباز البلاي أبي بكر محمد بن أحمد بن حمدان في يتيمة الدهر للثعالبي،

$r \leqslant 0 / r$

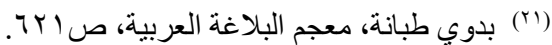

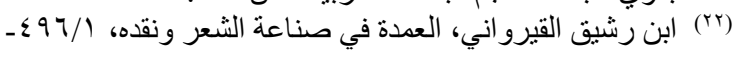

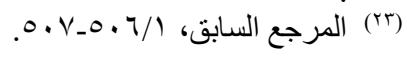

تفاصيله وإنما يلمح منها ما ينشئ في ذهنه معنى عامَّا يمكن أن يدرج فيه الثيء المنظور ، وقد قالوا للشيء الذي يراه الرائي من بعيد شخصٌ (^ا'). وإذا قصرنا النظر على مفردة (التلميح) وجدناهم يرون أنّ التلميح إشارة في فَحْوى الكلام إلى مَثَل سائر ، أو شعر نادر ، أو قصّة مشهورة على معنى أَنْ يكون في الكلام ما يَنتقلُ الذّهن منه إلى شيء من ذلك(19)، ويتوافق هذا المعنى الذي فسروا به التلميح مع مصطلح التناص. ويأتي التلميح عند البلاغيين درجة أولى في التحسين الأسلوبي، وفوقه يأتي التمليح الذي يتضمّن زيادة في المعنى كقول الثاعر:

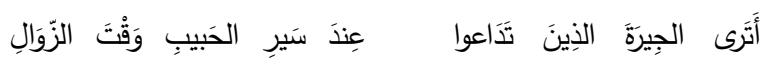

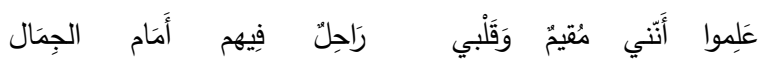

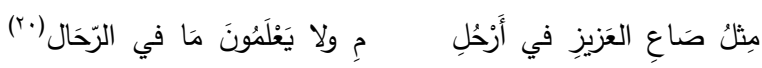
القَو

والمعنى غير المباشر في أبيات ابن المعتز إشارة إلى قصة يوسف عليه السلام مع إخوته عندما فُقِدَ صواع

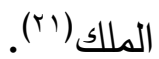
وقد وردت كلمة التلميح عند البلاغيين في كثير من الأبواب البلاغية؛ لأنّ البلاغة عندهم هي اللمحة الدالّة، ويعدّون التلميح من باب الإشارة الذي يقصده

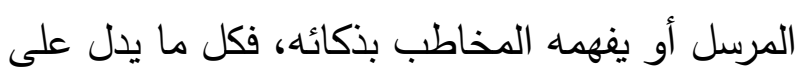

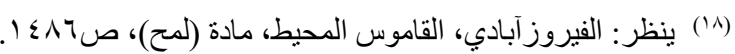

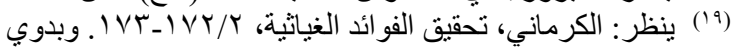

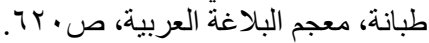

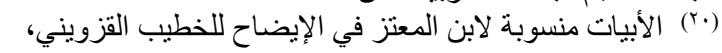

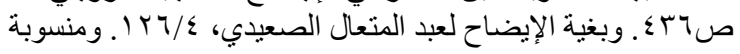


ولا يتمّ هذا التجاوز للمعنى الحرفي إلا بعد القيام بعملية

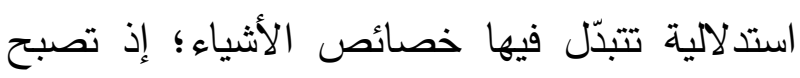

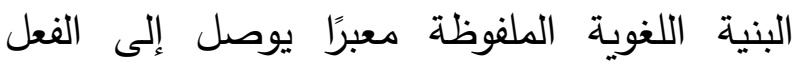
الإنجازي غير المباشر المقصود، وبذلك يكون المرسل إليه قد اكتشف غير المنطوق به من المنطوق دون أنْ يكون بينهما علاقة تضمّنٍ منطقيّة (rV).

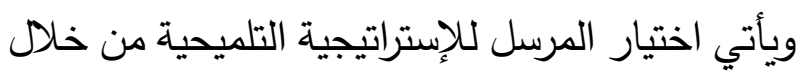
الدواعي السياقية التي تجعله يعدل عن استعمال الخطاب المباشر إلى استعمال الخطاب غير المباشر ، لدئه ويدفعه إلى ذلك عوامل كثيرة منها ما يتعلّق بذات

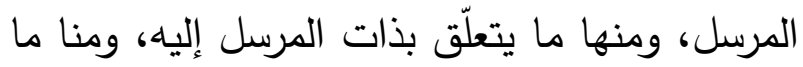
يتعلّق بالخلفيّات الثقافية والاجتماعية(r^) المبحث الثاني: طرائق التوظيف التداولي للبيت

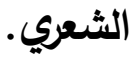

وظّف ابن رجب الحنبلي البيت الشعري بكثافة داخل خطابه الثارح للحديث النبوي، وقد وصل مجموع لئل

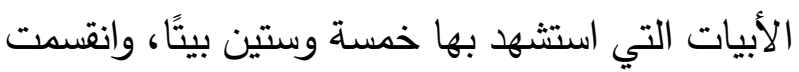
على غرضين كبيرين من موضوعات الشعر العربي

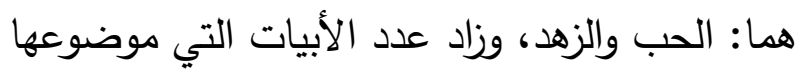

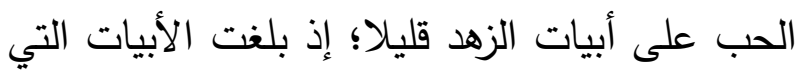

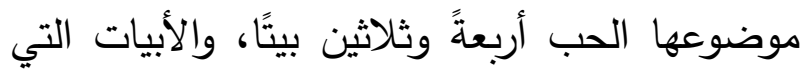
موضوعها الزهد واحدًا وثلاثين بيتًا.

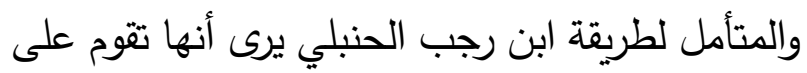

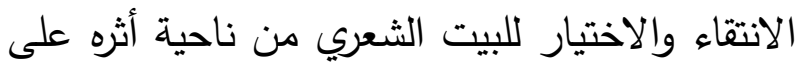

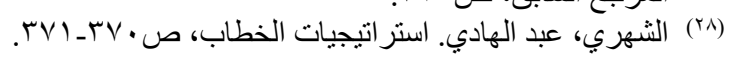

أسمائه في الإثارة، وأنّ للمخاطب فعلا في تلقّيه وتفسيره ومعرفة مقاصد المتكلم به، وهو ليس أمرًا سهلا على المتلقي تأويله إلا إذا عرف المصاحبات اللغوية وغير اللغوية للخطاب. ويعرف التلميح في معاجم المصطلحات الأدبية بأنه "تعبير مشتق من أصل لاتيني يعني التلميح، ويستخدم

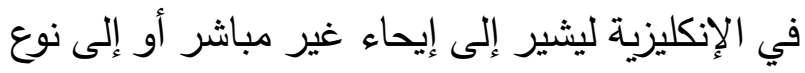

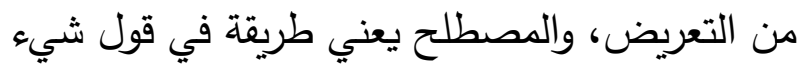
دون تقرير ذلك فعلا وصراحة(؟ء). وهو عندهم مرادف لمصطلح التعريض الذي هو عبارة

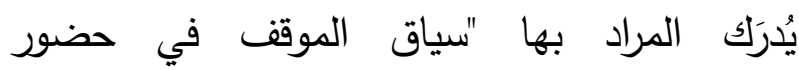
المخاطب... وتظل الدلالة في التعريض رهنًا بالموقف وعلاقات طرفي الحديث (المتكلم والمتلقي) وموضوعه، ويقع الفرق بين التعريض والأساليب

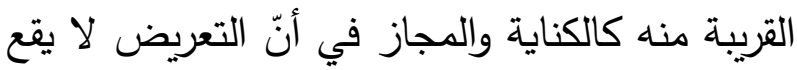

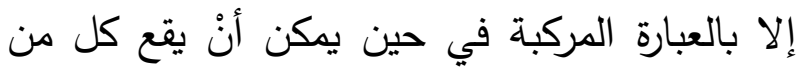
المجاز والكناية في اللفظ المفرد(ب0). وفي التداولية تعرّف الإستراتيجية التلميحية بأنّا

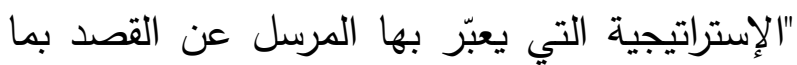
يغاير معنى الخطاب الحرفي لينجز بها أكثر مما يقوله إذ يتجاوز قصده مجرّد المعنى الحرفي لخطابه، فيعبّر عنه بغير ما يقف عنده اللفظ مستثمرًا في شلك

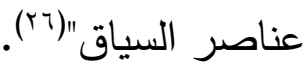


جاء فيه الاختيار السابق ورد فيه قول النبي صلى الله عليه وسلم: (وخالق الناس بخلق حسن)، وهذا الكلام مجمل، فانتقى ابن رجب الحنبلي متأثمًاً بانجذابه للتراث، ورضًا بما يختاره الأئمة من قبله هذه الأبيات التي فسّر بها سلام بن أبي مطيع حسن الخلق. ويكثف الاختيار عن مقصد آخر عند ابن رجب الحنبلي يلمح من أنّ هذه الأبيات لزهير بن أبي سلمى، ومضمونها يتحدّث عن الكرم الذي يتميّز به العرب منذ جاهليتهم، وتفسير حسن الخلق بهذه الأبيات يلمح منه أنّ ابن رجب يهتمّ بالأخلاق التي تقوم على تحقيق الصلاح الاجتماعي، وتحقق حسن التّواصل بين الناس. والشرط الثاني في عملية التوظيف التداولي للبيت الشعري تأتي من عملية نزع البيت من سياقه الخاص، وهي تجريد للنص الشعري من جمالية البناء الشكلي للقصيدة، ونزع له من دائرة الغرض الشعري الذي نشأ فيه، ونقل له من مقصد الشاعر إلى مقصد المخاطِب ضمن سياق الخطاب الجديد، ومن الشواهد على ذلك أنّ ابن رجب الحنبلي عندما ذكر خبر الجنيد الذي فيه: "قالت النار : يا رب، لو لم أطعك هل كنتَ تعذبني بشيء هو أشدُّ مني؟ قال: نعم، كنتُ أسلّط عليك ناري الكبرى. قالت: وهل نارٌ أعظم مني وأشدّ؟! قال: نعم، نار محبتي أسكنتها قلوب أوليائي"(·r) .

الاطلاع، ينظر : ديوان أبي بكر الثبلي، تحقيق: د. كامل مصطفى الثشيبي،

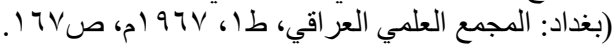

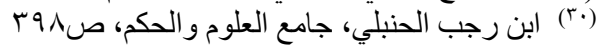

تطوير المعنى النثري، ومن ناحية صفته التراثية إذ كل الأبيات هي اختيار من الشعر الذي سبقه، وهذه الطريقة تقوم على تجريد الشاهد الشعري من سياقه الجمالي، ووضعه في سياق آخر يناسب مقاصده في

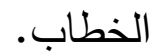

ويمكن أنْ نرى في طريقة توظيف الأبيات الشعرية في الخطابات أنّها تقوم على شروط ثلاثة لابد لمنشئ الخطاب أنْ يراعيها، وهي: الاختيار، والنزع، والتحويل. فالاختيار للشعر يقوم على ملاحظة فائدته في تحقيق مقصد المرسل؛ إذ إنّ الاختيار يكون في تلك اللحظة مبنيَّا على ما سيضيفه البيت الشعري إلى الخطاب الذي لا يريد المرسل أنْ يقوله بطريقة مباشرة، فيعد إلى توظيف ما يفهم منه أنّ له مقصدًا مغايرًا للوظيفة الإخباريّة في البيت، أو المقصد المباشر من الخطاب. ومن الشواهد على الاختيار أنّه وظّف خبرًا أدبيَّا يتضمن ثلاثة أبيات لزهير بن أبي سلمى، وهذا الخبر مرويّ عن سلام بن أبي مطيع عندما سئل عن حسن الخلق فأنشد: تراه إذا ما جئتّه متهلا

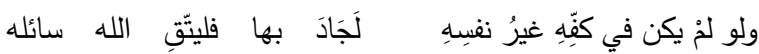

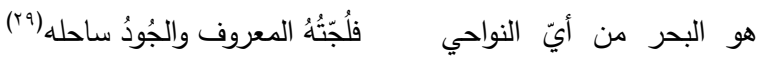
أتتانه إنّ اختيار هذه الأبيات جاء تفسيرًا للخلق الذي يفضّله ابن رجب الحنبلي؛ لأنّ الحديث الثامن عشر الذي

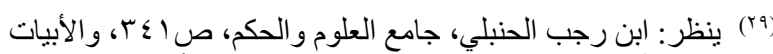

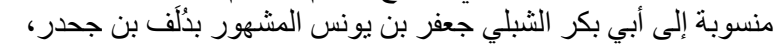

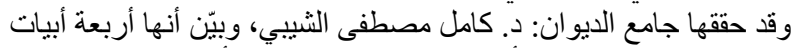

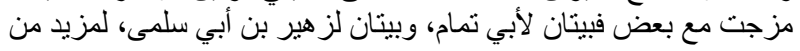


واقتران المتعة الجمالية في الشعر بالمتعة التعبيرية عبر إظهار المعاني في عبارات مستحسنة للنفس في

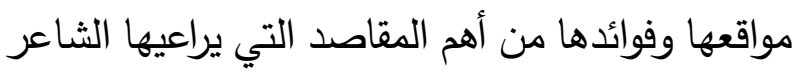
ويهدف لها، فيقوم بتشكيلها وفق علاقات تركيبية خاصة مكونة من معجمه اللغوي وتجربته الحياتية ورؤيته الذاتيّة(عَ). ولا يقتصر التوظيف الجمالي للبيت الشعر على لئه الثاعر في قصيدته بل يمتدّ ذلك للخطاب من خلال

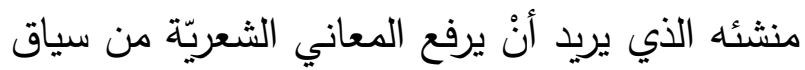
الثكل الشعري، ودائرة الغرض الشعري إلى سياق

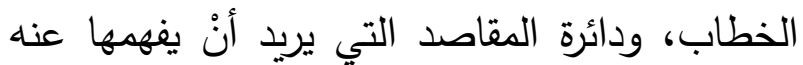
المرسل إليه حتى تصل رسالته من جهة التداخل بين

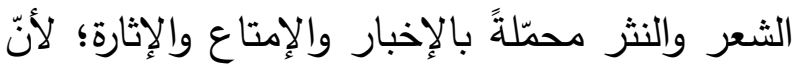
خطاب ابن رجب الحنبلي يحاول تحقيق الأثر في نفس والإتسار والان المرسل كما يحدث ذلك له عندما يقرأ الثعر • وقد أشار حازم القرطاجني إلى وظيفة من وظائف الثعر تقوم على أنّ "المقصود بالثعر الاحتيالُ في تحريك النفس لمقتضى الكلام بإيقاعه منها محلّ

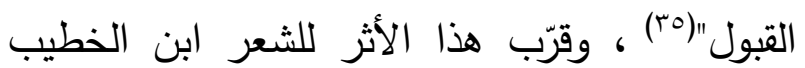

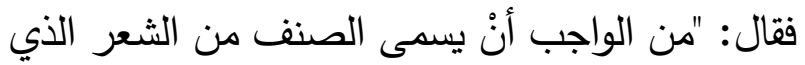

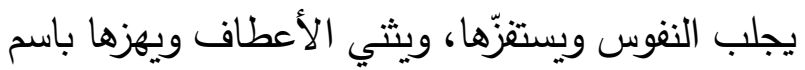

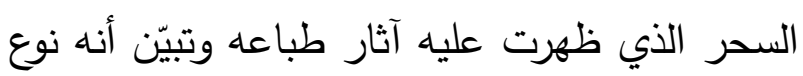
من أنواعه"(rr).

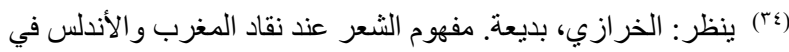

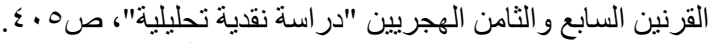

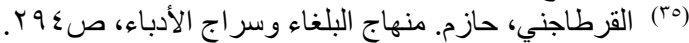

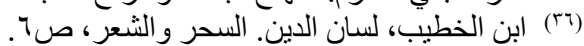

ثم قال ابن رجب الحنبلي بعد الخبر : "وفي هذا يقول

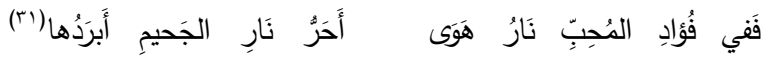
وقد ورد بيت أبي الطيب المتنبي في قصيدة غرضها المدح لمحمد بن عبيد الله العلوي، ومعنى البيت يقوم

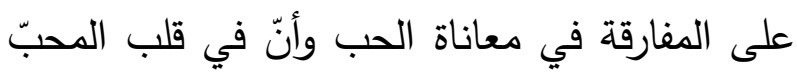

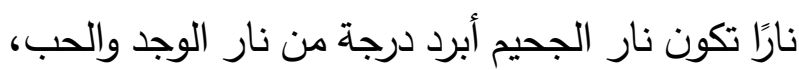
وهنا يظهر أنّ ابن رجب الحنبلي انتبه إلى أنّ المعنى

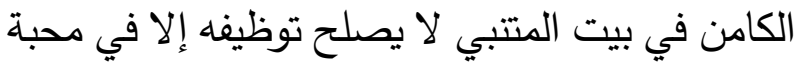

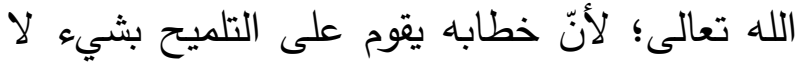
يصل الخطاب النثري إلى بيان كنها وحقيقته. ومراعاة المقصد في التداولية أمر محوريّ؛ لأنه السبب لبئن الذي يجعل المرسل يهنمّ ببلورة المعنى في كلامه، ومراعاة كيفية التعبير عن قصده من خلال اختيار ما يناسب غرضه، ويتقق مع لغة خطابه، ويحقق التفاعل

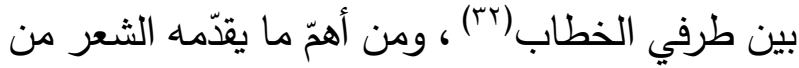

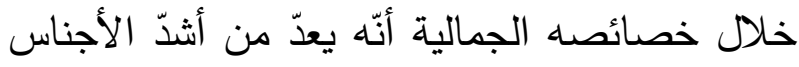
الأدبية تحريخًا للنفوس؛ لما ينطوي عليه من محاسن تأليفية تبرز في إيقاعه المتتالي، ونغمه العروضي لماني

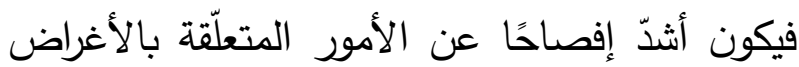

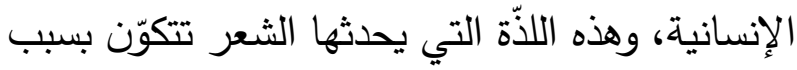
توصيله المعنى مقرونًا بلذّةٍ حسيّة تدخل للنفس عن الِّنس

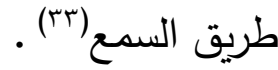

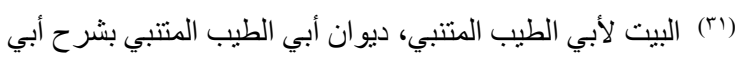

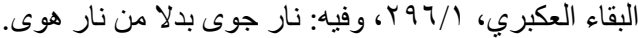

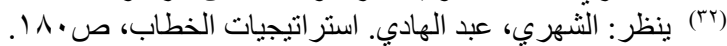

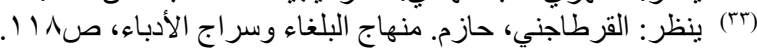


النثري يشعر بأنّ المرسل يبحث عن متلقِّ نموذج

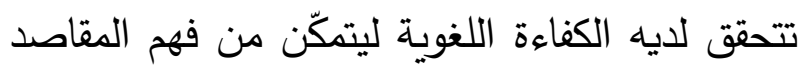

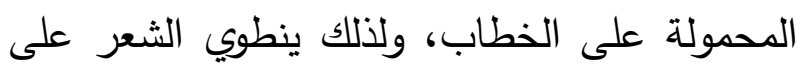
عنصر جوهري بالغ الأهمية في تقدير طبيعة الأثر

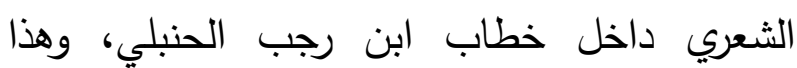
العنصر هو عنصر الإيقاع الذي يدخل للنفس عن طريق الحس، وهو أعظم ما يمكن للمرسل أنْ يوظّّه من أجل تحسين مواقع المعاني في النفوس، ويصبح الإيقاع في الثعر قيمة تواصليّة بين طرفي الخطاب

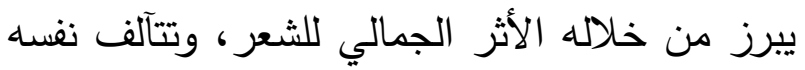
مع المعاني المطروحة، ويتحقق التقاعل بين المرسل والمرسل إليه من ناحية التلميح، وفهم الإشارات

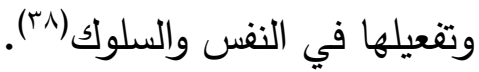
وتوظيف البيت الشعري داخل الخطاب يعمل على إعادة التفكير بالنّص لا من خلال كونه نصَّا يحدث لذّةً للنفس فقط، بل من خلال كونه تحول إلى مصدرٍ

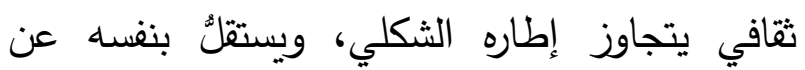
غرضه الشعري، فيكون غرضًا مطروحًا لغايات المتكلمين ومقاصد الأدباء والمترسلين، وبذلك نجد في غئلي البيت الشعري مسوّغات تمكّنه من أنْ يتحقّق به ونداه

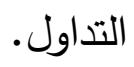

ومن هذه المسوغات أنّ البيت الشعري لابد أنْ يمثّل

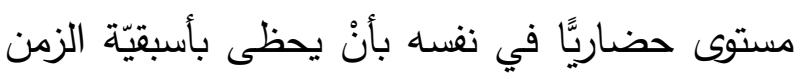

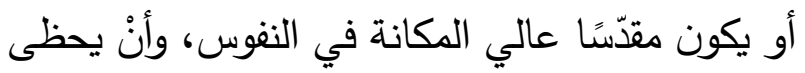
قائله بفضيلة السبق الزمني أو التّيّز الاجتماعي، وأنْ
ومن الجوانب الخفيّة في توظيف البيت الثعري داخل الخطاب -بوصف الشعر أكثر الأجناس الأدبية اشتغالا باللغة المجازية- أنّ المجاز كما يرى السجلماسي: "هو القول المستفزّ للنفس المتيقن كذبه، المركّبُ من مقدّمات مخترعة كاذبة تخيّل أمورًا وتحاكي أقوالا"(rV) ، ومفتاح عبات منترته السابقة قوله:

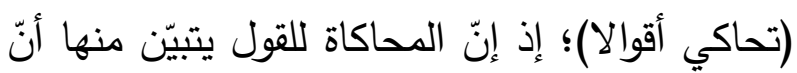

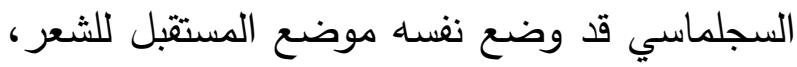

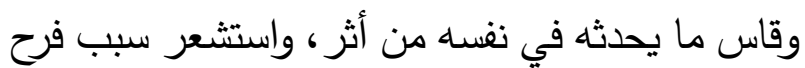
النفس وارتياحها للشعر بوصفه خطابًا يقوم على تفعيل المجاز إلى أقصى غاياته، فوصف ما يحدث له من له

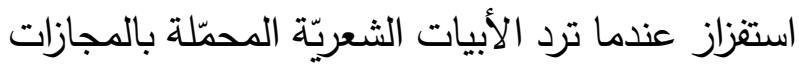
على النفس إذ إنّ النفس تشعر بأنّ هذه الأقوال لها لهات التهات

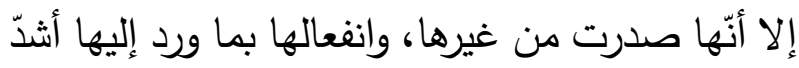

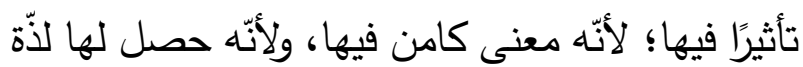
حسيّة عندما ورد إليها من خارج دائرتها. والثرط الثالث الذي قام عليه توظيف البيت الثعري أنّ صاحب الخطاب يقوم بتحويل البيت الشعري من

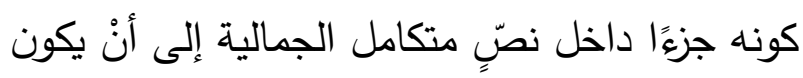

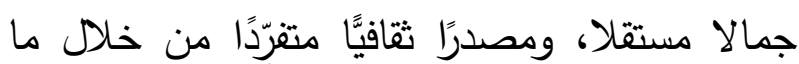

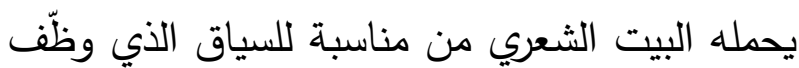
فيه، ومناسبة للمقصد الذي يريد المرسل أنْ يؤدي به ليه لئه لغته الأخرى التي تقف وراء الجمل.

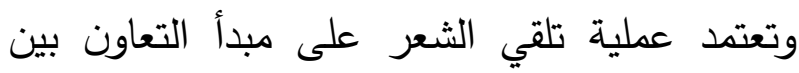
طرفي الخطاب؛ لأنّ توظيف الشعر في الخطاب

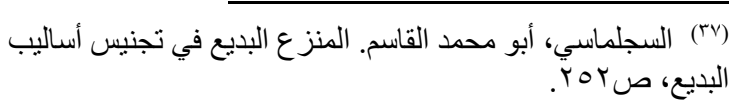


الختام إنْ لم يعتِن به صاحب الخطاب أنسى محاسن ما قبله، وانتهى إلى أنْ يكون مضمونه مثله مضل مضدمون

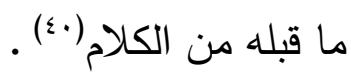

وذكر بعض النقاد أنّ الختام يجب أنْ تتوفر فيه نغمة

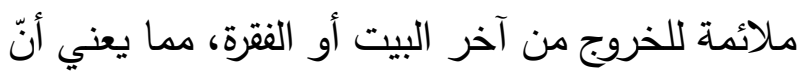
من أهداف توظيف البيت الشعري أنْ يحدث نغمةً

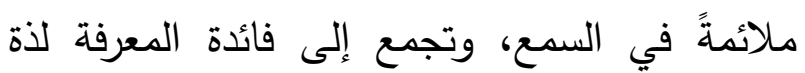
الإيقاع الثعري الذي ينهض بتحريك النفوس ويستيرها

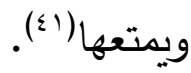
ولا يمكن أنْ يكون كتاب ابن رجب الحنبلي (جامع

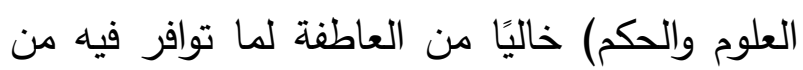
الفنون النثرية حتى إنّ وصف أسلوبه بالنثر الأدبي قد ماند لا يجاوز الحقيقة؛ لأن من خصائص النثر الأدبي قوة العاطفة المؤثرة في العبارات والصور والتراكيب والاختيارات، وهو كتاب يتحدث في شرح الحقيقة

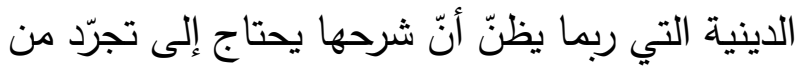

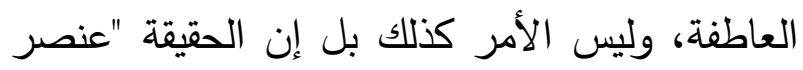

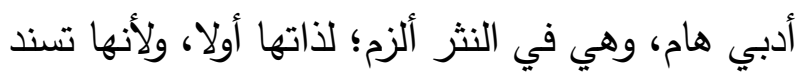

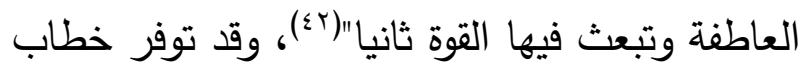
ابن رجب في شرح الحديث النبوي على عنصري القوة العقلية، والجمال الأدبي. وقد جاء ختام شرح الحديث عند ابن رجب الحنبلي

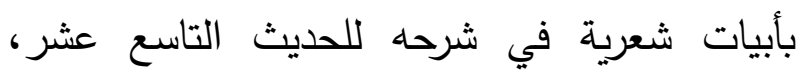
والحادي والثثلاثين، والسادس والثلاثين، والأربعين، لتئ،

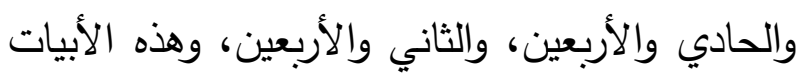

يحظى بسيرورة بين الناس تحقق له الوجود بصفته من المعارف السابقة للذهن التي يمكن أنْ تسهم في تغذية لتهن

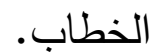
وقد أشار القرطاجني -وهو يتحدث عن الثاعر - إلى

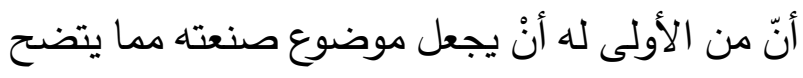

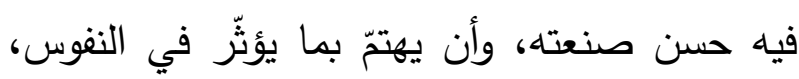

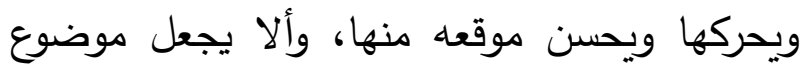
صنعته دليلا على ضعفه بسبب عدم تحريكه

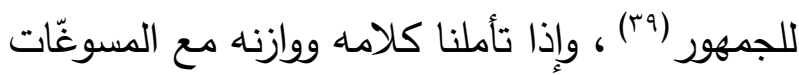
السابقة ظهر أنّ الخطاب صناعة مثل صناعة الثعر بل هو أوسع منذ؛ لسهولة مزج الأجناس الأدبيّة فيه، والتتويع في عرض الفكرة بقوالب لغويّة متعددة، والاستفادة من خصائص الأجناس الأدبيّة في تحريك لفيك

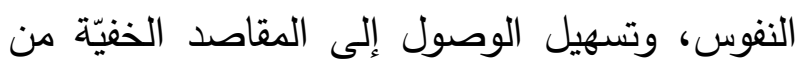

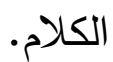
ومن طرائق ابن رجب الحنبلي في الاستفادة من البيت الشعري تداوليَّا أنه يجعله تام خطابه في شرح الحديث، وينتقل منه إلى الحديث الذي يليه، وهذا الأسلوب

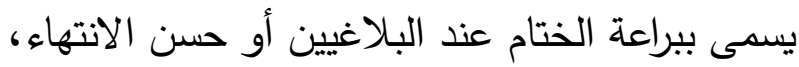
ويتضمّن هذا الختام نهاية الكلام في الخطاب.

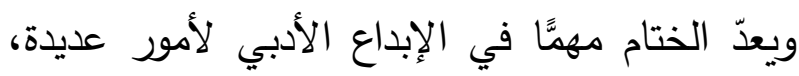

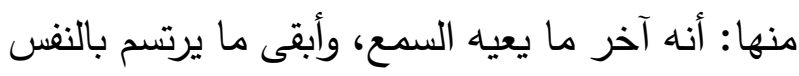

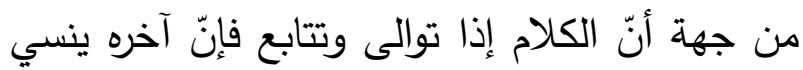

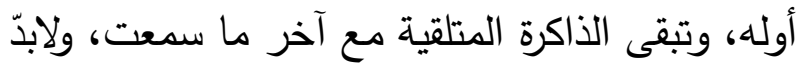

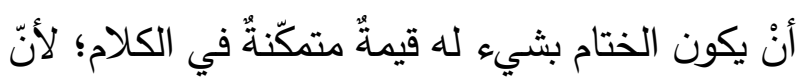

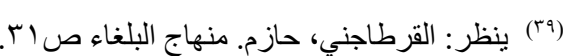

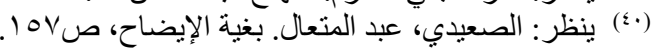


بيت يصوّر الحياة الدنيا بالجيفة فيقول في شرحه لحديث النبي صلى الله عليه وسلم " ازهَد في الأُنيًا

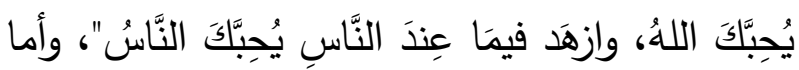

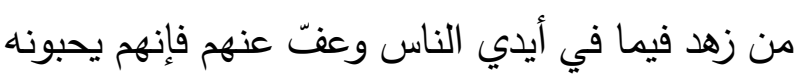
ويكرمونه لذلك ويسود باه عليهم كما قال أعرابي لأهل

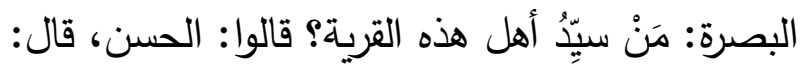
بم سادهم؟ قالوا: احتاج الناس إلى علمه، واستغنى هو

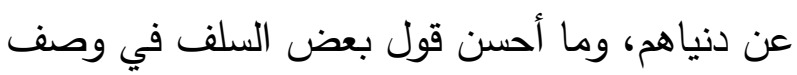
الدنيا وأهلها:

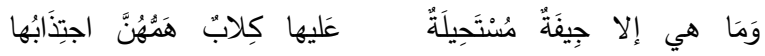

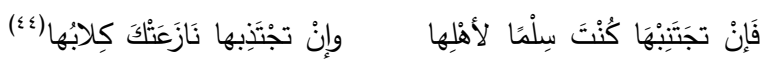

ويظهر التوافق بين المعنى العام للحديث والمعنى الثعري إلا أنّ خطاب ابن رجب يلمّح إلى تصوير حقيقة الحياة في الخيال، ويتغي إنشاء صورة بشعةٍ

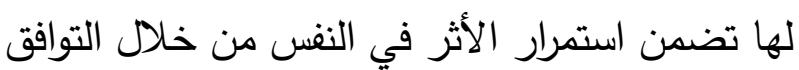
بين إيقاع الثعر وطبيعة النفس فيستوعب الفكر حقيقة الحياة، ويستلهم الضمير صورتها المشابهة في الواقع

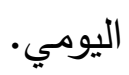
وإذا نظرنا إلى الأبيات الشعرية التي جاءت في موضوع الحب وجدنا علاقة ظاهرةً بين المعنى الحرفي للحديث والمعنى الشعري للبيت ومن ذلك شرحه

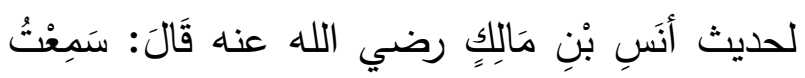

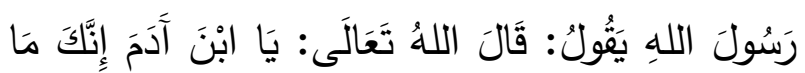

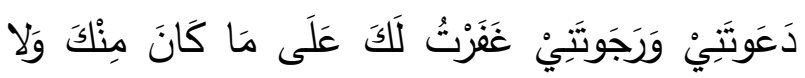

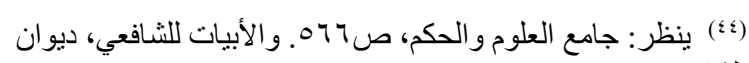

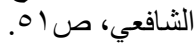

الثعرية منها أربعة في موضوع الزهد، واثنان في

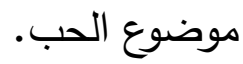
ومن الثواهد التي أوردها في موضوع الزهد أنه ذكر

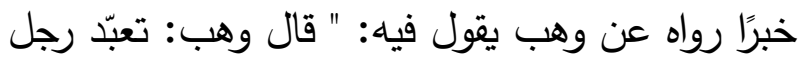
زمانًا، ثم بدت له إلى الله حاجة، فصام وهام سبعين سبتًا، يأكل في كل سبت إحدى عشرة تمرة، ثم سأل الله

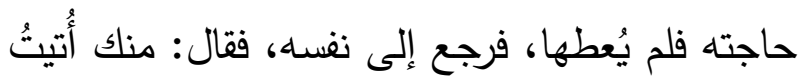

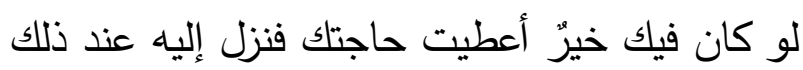
تَلَكُ فقال: يا ابن آدم، ساعتك هذه خيرٌ من عبادتك التي مضت، وقد قضى الله حاجتك. خرجه ابن أبي الدنيا، ولبعض المتقدّمين في هذا المعنى:

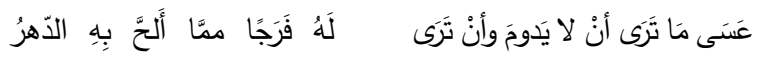

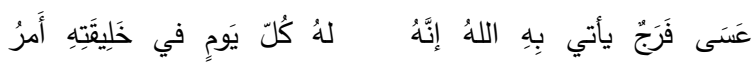

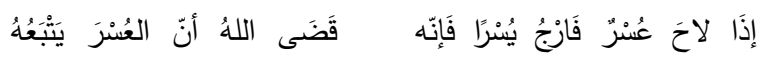

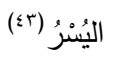

ويظهر من الختام التوافق بين مضمون الحديث الذي يقول فيه النبي صلى الله عليه وسلم لابن عباس: (احفظ الله يحفظك) ومضمون الأبيات الذي يسمو

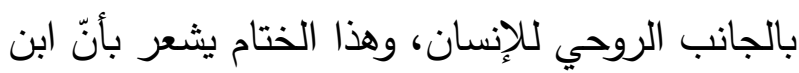

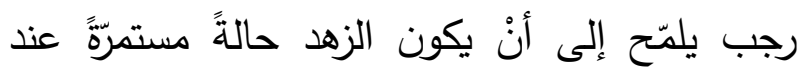

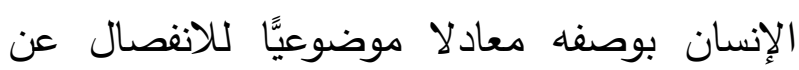

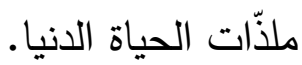
وفي حديث آخر يكرر ابن رجب التأكيد على فكرة

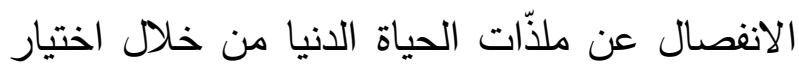

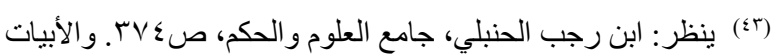

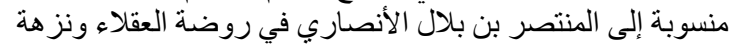

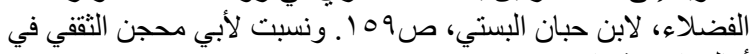

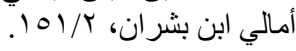


العبادة يقوم على الانفصال والاتصال؛ الانفصال عن

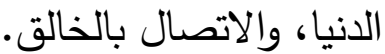

وإذا كان الانفصال عن ملذات الحياة الدنيا زهدًا فإنّ

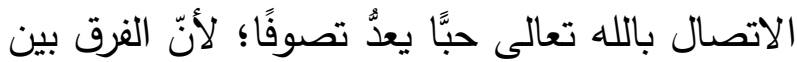
الزهد والتصوف يكون من حيث الغاية والفكرة؛ فالفرق بين الزهد والتصوف في الغاية يأتي من أنّ الزاهد يترك

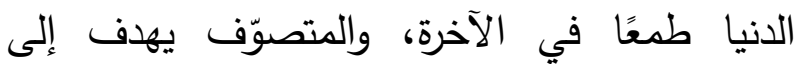
الاتصال بالله تعالى في هذه الدنيا. ويظهر الفرق بينهما في النكرة من أنّ الزاهد يتعامل مع الله تعالى من خلال الخوف من قوته وغضبه وبطشه وانتقامه، والمتصوّف يطمئنّ إلى الله تعالى تلى من خلال محبّّه، والرضا بقضائه وقدره، والتسليم لتدبيره ولطفه وكرمه، وهذان هما جناحا الؤمن في

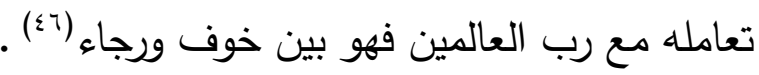
والمتأملا للانتهاء من شرح الحديث النبوي عند ابن رجب الحنبلي يدرك أنّه يقّم أمرين؛ أولهما التثقيف التيف

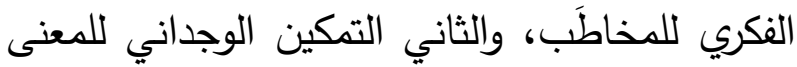
النبوي عبر تتويع الخطاب بين النثر والثعر ، وتصبح الثبح

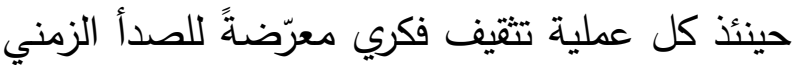
إنْ لم يمتزج بها انفعال، أو يعقبها تمكين وجداني،

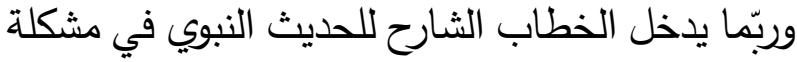

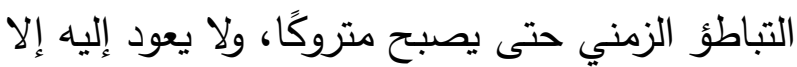
من كان باحثًا عن معلومة أو منقطعًا للعمل، ويصبح لتصني الهدف الثقافي معرّضًا للزوال.

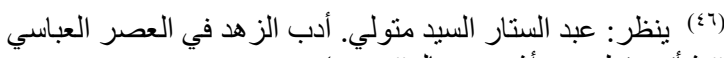
"نشأته وتطوره وأنشهر رجاله"، صئ.

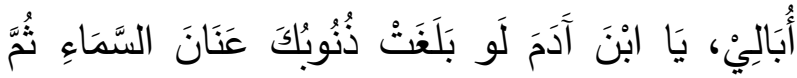

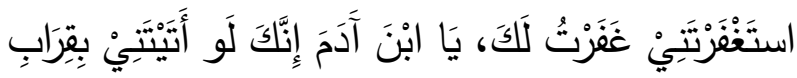

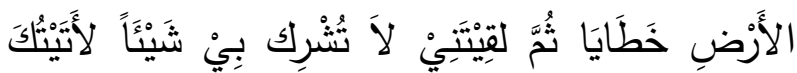

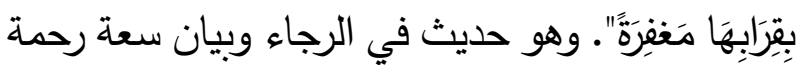
الله تعالى ومغفرته، واختار ابن رجب الحنبلي أنن يختمه بقوله: "إذا علقت نار الدحبة بالقلب أحرقت منه كل ما سوى الرب عز وجل...

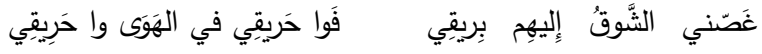

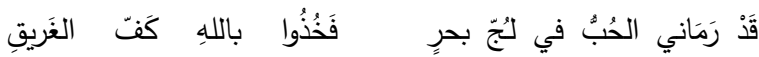

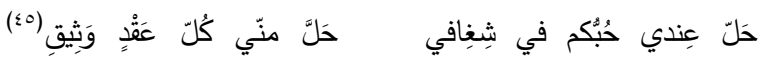
والتناسب واضح بين النصين إلا أنّ الخطاب في البيت الشعري يلمّح إلى أنّ الذنوب عقدة تيّيّ الإنسان

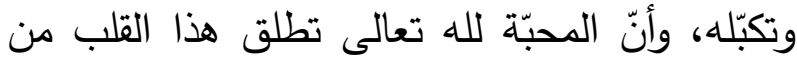
أسره، وتجعله يستعذب مرارات الحياة في ذات الله تعالى، فيكون له سلوةً من الهموم، ونجاةٌ من الكروب فئس

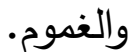
وتوظيف البيت الثعري في سياق الزهد والحب يلمّح إلى أنّ الزهد لابد أنْ يتطوّر إلى الحب؛ لأنَّ الزهد

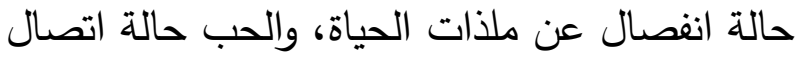
بخالق اللذّات كلها، بل إنّ الاتصال به هو لذّة لا لا تعادلها لذّة أخرى. ولذلك يتضمن خطاب ابن رجب الحنبلي الذي وظف فيه الأبيات الشعرية من موضوعي الزهد والحب تلميحًا إلى منهج عمليّ في الوصول إلى إدراك اللذة في 
بالاهتمام التداولي من جهة التّلفظ، بمعنى: إنّ أهمية المتكلم في التداولية لا تأتي من موقعه في العملية التواصلية بل من موقعه في زمن التّلفظ. وتتظر التداولية للمفردات اللغوية بوصفها علامات تتضمن معانٍ حرفيّة، ومعانٍ استعمالية؛ فالمعاني الحرفية معانٍ أوليّة تدريسيّة يمكن التكوين المعرفي من خلالها للعقل، أما المعاني الاستعمالية فهي معانٍ غائيّة اجتماعيّة يمكن اكتشاف الذكاء الشخصي في أطراف الخطاب عبرها، ومن هنا يأتي تعريف التداولية بوصفها "العلم الذي يدرس المعنى مع التركيز على العلاقة بين العلامات ومستعمليها والسياق أكثر من اهتمامها بالمرجع أو الحقيقة أو بالتركيب"(^؛). وتظهر أهمية الإشاريات من علاقتها بأزمنة الملفوظات؛ لأنها تتضمن المعنى الحرفي، والمعنى الاستعمالي الذي يقوم السياق ببنائهما في الخطاب مما يجعل المتأمّل للإشاريّات يقف أمام ظاهر إشاريّ أوليّ، وباطن إشاريّ مستقرّ داخل العلامة اللغويـة. وتوضع الإشاريات في التداولية ضمن درجة أولى تتركّز مهمتها في فهمها بوصفها رموزًا مبهمةً تقوم ظروف استعمالها في السياق بكثف دلالاتها؛ لأنها مرتبطة بسياق التّلفظ وزمنه، والذوات التي تحضر أثناء الخطاب(9)؛ (9). وإذا كانت العلاقة ذات أهمية كبرى بين المتكلم والمتلقي في العملية التواصلية، والاستعمال التداولي للإشاريّات فإنّ ذلك لا يخرج كله عن إدراك مفهوم
إنّ حضور النص الشعري في الخطاب يمنحه ديمومة الصناعة الشعريّة التي تمسّ الطبائع؛ لأنّ الطبائع متكرّرة، والعقول المفكّرة متغيّرة بما يرد عليها من ثقافات أو مشغلات، وهذا ليس موجودًا في الثعر الذي يعدّ رفيق المواقف التي تشعر الإنسان بإنسانيته عندما يتذكر بيتًا من الشعر يختصر المدى، ويكثف توافق الإنسان مع أخيه منذ نشأة البيت عند صاحبه حتى لحظة إنشاده أو روايته مرةً أخرى. المبحث الثالث: البعد الإشاري لتداولية البيت الشعري. تتناول التداولية المحددات المتعلقة بلغة الخطاب من خلال السياق، وتهي تتظر في ذلك تراعي أطراف العملية التواصلية الثلاثة: المرسل والرسالة والمرسل إليه، وتضم إلى ذلك ما يحف بالخطاب من سياقات خارجيّة تسهم في تحميل الخطاب مقاصد أخرى للمرسل قد لا ينهض بها المعنى الحرفي للخطاب. ثم إنّ التداولية الإشارية تعني تلك الضمائر التي تخصّ الذوات الواردة في الخطاب، وتحاول تحديد علاقتها ببعضها عبر محوري: الحضور والغياب، وموقعي: المكان والزمان عبر النظر إلى التّلفظ بوصفه المعيار المهم في فهم تداولية الخطاب اللغوي. ويرى التداوليون أنّ أهمية التداوليّة تكمن في الجانب الوظيفي والسياقي للخطاب، ففي الجانب الوظيفي نكتشف المعنى الحرفي للغة، وفي الجانب السياقي نكتشف المقصد الخاص بالمتكلم( (₹)؛ لأنها هو المعنيّ 
الداخلية التي تعمل على إيجاد نوع من الانسجام والتّماسك بين تلك العناصر ، وتسهم الروابط التركيبية، والروابط الزمنية، والروابط التركيبية في تحقيقها"(or)

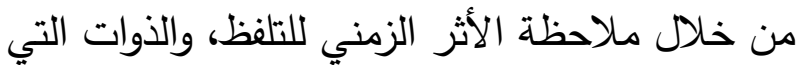
تأخذ واقعها بين الحضور والغياب. وتتقسم الإشاريّات في التداولية إلى ثلاث إشاريات: إشاريّات شخصية، وإشاريات زمانيّة، وإشاريات مكانية(or)

وفي خطاب ابن رجب الحنبلي يمكننا أنْ نحظى بعدد

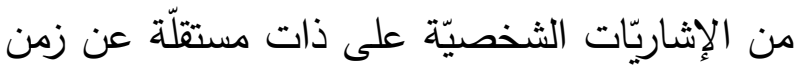
التّلفظ لكنها ضمن الخطاب الواقع بين المتكلم (ابن رجب) والمخاطب.

ومن أبرز الإشاريّات الثخصية الضمير الغائب (هو)، وظهر في الخطاب بعدّة أشكال منها: أنْ يكون الإندات

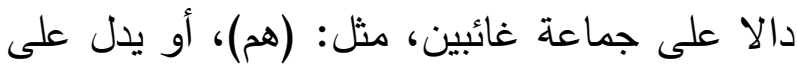
مفرد غائب، مثل: (هو)، ولكنها تظهر في السياق متصلة بكلمة (بعض) مع الضمير الدال على جماعة الغائبين (هم)، فيكون: (بعضهم) هو الثكل اللغوي

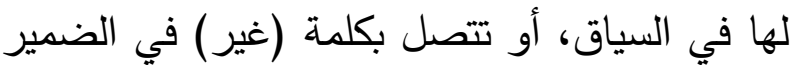
المفرد الغائب، فيكون (غيره) هو الثكل اللغوي لها في السياق، ويأتي الضمير الغائب مستترًا في الفعل المضارع (ينشد)، أو الماضي (أنشد). وهذا العنصر عند ابن رجب الحنبلي يحيل على الغائب بوصفه ذاتًا غائبة عن زمن التلفظ في الخطاب
سياق التّلفظ الذي يبدأ باللحظة الزمنية لتحديد المعاني الكامنة في هذه الإثاريات، وهو الذي يمنح الخطاب وضوحًا كبيرًا لم يكن يحصل له لو لم يقم السياق بدوره في التفسير والتبيين والإيضاح. ويرى أحد الباحثين أنّ الإشاريّات تتدرج ضنمن الإضياح،

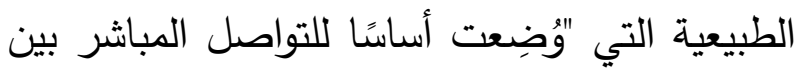
الناس وجهًا لوجه، كما تظهر أهميّتها البالغة حين يغيب عنّا ما تشير إليه فيسود الغموض ويستغلق الفهم" (0.). وتعني الإشاريّات "كل ما يشير إلى ذات أو موقع أو

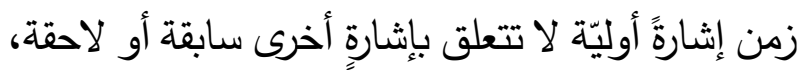

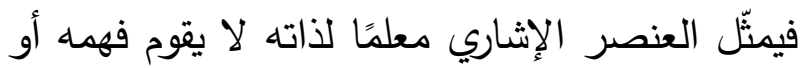
إدراكه على غيره"(10)، بل يتعاون المعنى الحرفي لإني والمعنى السياقي على التلميح للمتلقي بما يؤشّر إليه

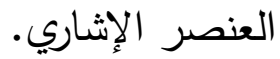
ويمكن أن تقرأ الإشاريات من خلال التعريف السابق على أنها تحمل في ذاتها دلالاتها الحرفيّة، وتحمل في لإني استعمالها دلالاتها التفاعلية؛ لأنّ كون العنصر الإشاري معلمًا لذاته يشعر بأنّه مكتفٍ بنفسه عن العناصر اللغوية الأخرى، ويستمدّ معناه التداولي من خلال ارتباطه بزمن التّلفظ، وصفات الذوات التي يحيل عليها. ويأتي النّص في المفهوم التداولي بأنّه متألّف من عدد

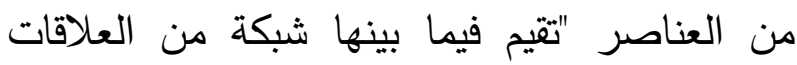

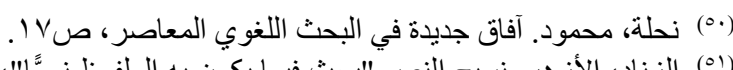

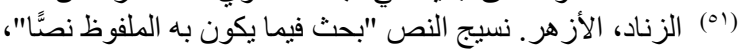


عطل عليّ الهموم وحالف بيني وبين السهاد وشوقي إلى النظر إليك أوثق مني اللذات وحال بيني وبين الشهوات، فأنا في سجنك أيها الكريم مطلوب، وفي هذا يقول بعضهم:

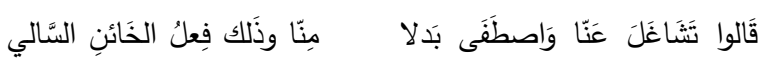

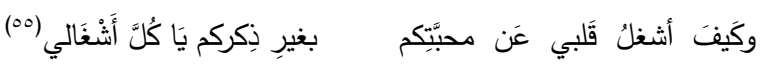
يأتي التأشير إلى الثخصيّة الغائبة في مستوى الغياب، وطرفا الخطاب هما المتكلم والمخاطب حاضران، والدلالة التّلميحية تؤدي إلى أنّ مقصد ابن رجب الحنبلي هو تلقين المخاطب غير ما يتضمنّه الفعل الإخباري للخطاب، ويكون التلميح إلى بيان أهمّية القول المنقول في مقابل الذّات، فالحقّ لا علاقة له بالذوات، بل يتبيّن الحق من محتواه وما يتضمنّه من الخير الذي تدركه الفطرة السليمة. ويضيف استعمال العلامة التأشيرية للغائب أنْ يصبح الخطاب بين ذاتين هما: ذات الغائب بوصفها المتلفظ الأول بالبيت الشعري، وذات التلقي التي تجمع بين ذات المرسل (ابن رجب)، وذات المخاطب (المتلقي لخطاب ابن رجب)، ويحدث بسبب الثنائية تقابل بين

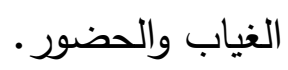
والملمح الذي يضمره الخطاب بهذه الإشاريّة للغائب هو أنْ يكون المرسل والمرسل إليه متضاميّين، ويمثّلنان موقع (نحن) في مقابل موقع الغائب (هو)؛ لأنّ خطاب ابن رجب الحنبلي يريد صنع توافق على سلى

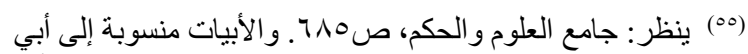

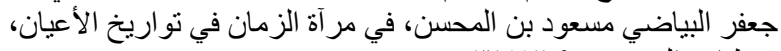

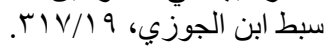

الذي وظّف فيه البيت الشعري، لكنه يحظى بالحضور في الخطاب عبر إعادة إنتاج القول الشعري وحكايته، وعند ذلك يقع الغائب الذي تلفظ بالبيت الشعري ضمن العلاقة التواصلية بين منشئ الخطاب (ابن رجب) ومتلقي الخطاب (المخاطب)، فيصبح لدينا ثلاثة ذوات: ذات المتكلّم، وذات المخاطب، وذات الغائب. وعندما ننظر للغائب من خلال زمن التّكلم يظهر أنّ الغائب حاضر بقوله في زمن الخطاب وغائب بذاته، وطرفا الخطاب حاضران في زمن الخطاب، وغائبان عن الإدلاء برأيهما أو مناقشة القول الشعري للغائب، وبذلك يكون في الخطاب مستويان: مستوى الحضور وفيه المتكلم والمخاطب، ومستوى الغائب وفيه الغائب صاحب البيت الشعري. ومن الشواهد على ذلك ما أورده ابن رجب الحنبلي في شرح الحديث الثامن والثَلاثين عَنْ أَبِي هُرَبْرَةَ رضي

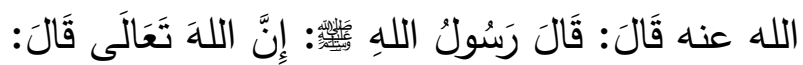

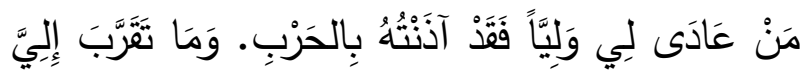

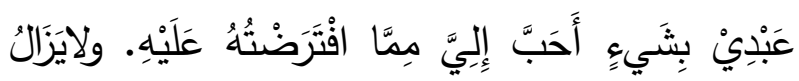

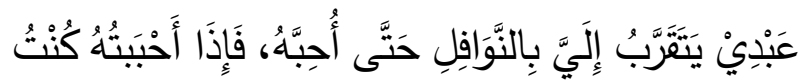

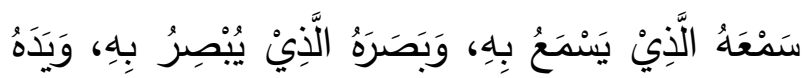

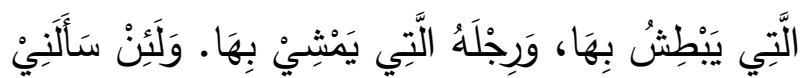

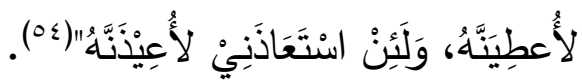
وقد أورد ابن رجب الحنبلي خبر داود الطائي أنبه كان يُنادي بالليل: "كان داود الطائي ينادي بالليل: همك

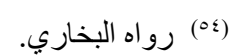


الحنبلي: "فإذا قوي حال المحب ومعرفته لم يشغله عن الذكر بالقلب واللسان شاغل فهو بين الخلق بجسمه وقلبه معلق بالمحل الأعلى كما قال علي رضي الله عنه في وصفهم: صحبوا الدنيا بأجساد أرواحها معلقة بالمحل الأعلى... وقال غيره:

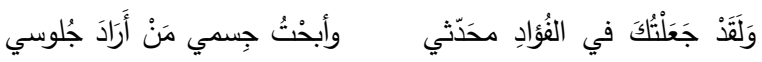

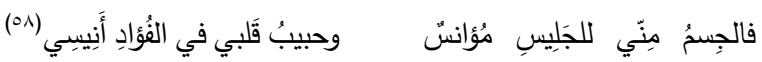

تظهر الإشارية للغائب في لفظ: (غيره)، وإذا قرأنا

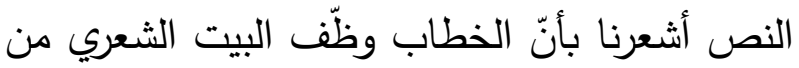

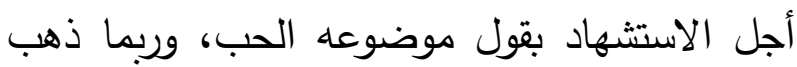
الظنّ إلى قضية التِّنّن في الكتابة، وتكثير الشواهد،

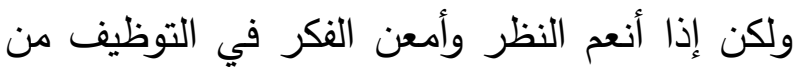
خلال زمن التّلفظ يتبيّن أنّ ابن رب ليس المتلفّظ الحقيقي بالبيت الشعري بل هو عبارة عن واسطة ناقلة بين المتلفظ الحقيقي والمتلقي الفعلي للخطاب، وهنا يصبح دور ابن رجب الحنبلي الانضمام للمتلقي بوصفه مستقبلا معه؛ لاتفاقهما في الانفصال عن زمن التلفظ بالبيت الثعري. إنّ ما يقوله التأشير للغائب مختلف عمّا يقوله الخطاب؛ لأنّ الإشاريّة يلمح بها المرسل إلى أنّه في

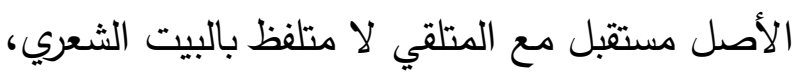
وهنا يظهر أنّ ابن رجب الحنبلي يضمر في هذا النقل

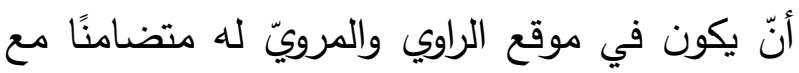
المتلقي لخطابه في التّعلم من الغائب المؤشّر إليه.

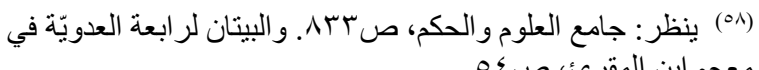

الماضي بوصفه معلمًا للحاضر الذي يجمع بين

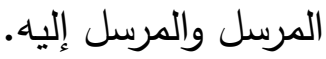
والنظر إلى الإثاريّات من خلال إدارك زمن التّلفظ في توظيف الأبيات الثعريّة يظهر خطاب المرسل بصورةٍ

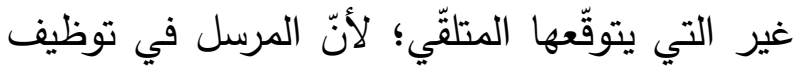
الأبيات الشعرية ليس منشئًا لخطاب جديد بل مكررًا لخطاب ماضٍ، وهذا التكرار يجعله متّحدًا مع المتلقي للخطاب في التلقي فيصبح مرسلا ومرسَلا إليه، أي: يكون ذا وظيفتين: وظيفة إرسال، ووظيفة استقبال؛ لأنّ المرسل (ابن رجب) ليس الذات المتكلّمة بل هو ذات متلقية وناقلة للخطاب. وهذه الإثاريّات ساعدتنا على كثف المقصد المضمر في الخطاب للمرسِل؛ لأنّ الإشاريّات "مفهوم تداوليّ يجمع كل العناصر اللغوية التي تحيل مباشرة على لإنى المقام من حيث وجود ذات متكلّمة، وزمان التّكلم، ومكانه ومن ثّ فلا بد من استحضار السياق المكاني والزماني والثخوص لتحديد الإشاريّات"(104). ويمكن إدراك قوة الإشاريّات في الكثف عن المقصد الخاص بالمرسِل من خلال إدراك موقعه من زمن

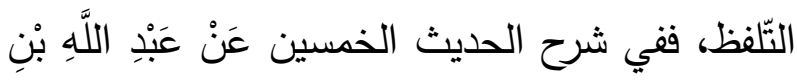

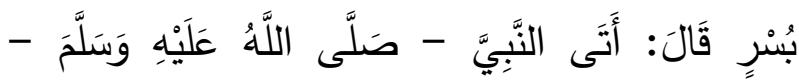

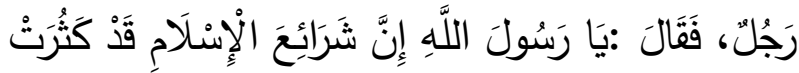

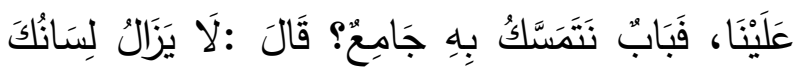

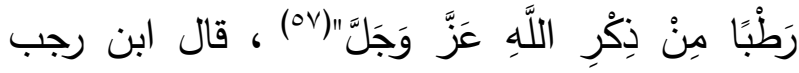

$$
\begin{aligned}
& \text { (T) العزاوي، كاظم. التعبير الإشاري في الخصيبي "مقاربة تداولية"، }
\end{aligned}
$$

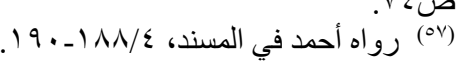


عَابِرُ سَبِيِلٍ .وَكَانَ ابْنُ عُعَرَ يَقُولُ :إِذَا أَمْنَيْتَ، فَلَا

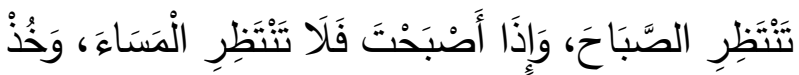

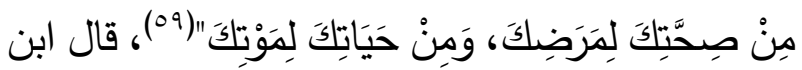

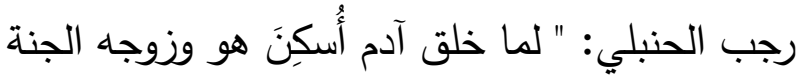

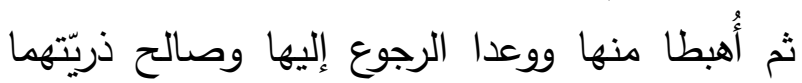
فالمؤمن أبدًا يحنّ إلى وطنه الأول، وحب الوطن الوطن من وصن الإيمان... ولبعض شيوخنا رحمه الله:

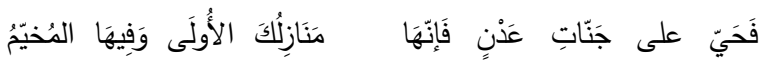

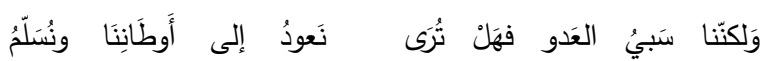

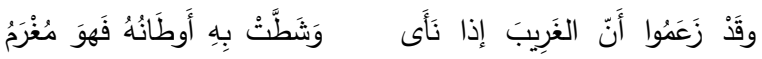

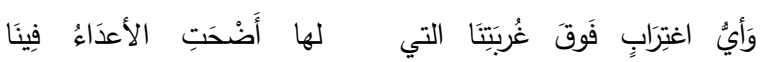

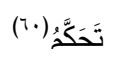

إنّ الإشارية بضمير الجمع للمتكلمين تدل في معناها

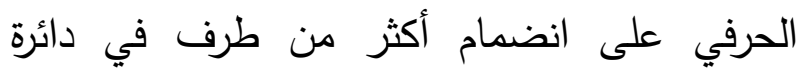
الضمير ، أو هو من تضخيم الذات عند المرسل، ولكنّ هني النظر لهذا الضمير من خلال زمن التّلفظ يشعرنا بأنّ الضّن

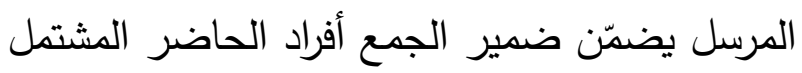

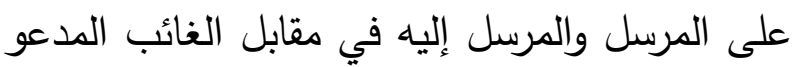
له بالرحمة، وليس هدف المرسل هنا نقل البيت الثعري بل إثارة التّعاطف مع الغائب من خلال مستوى الحضور والغياب، ومستوى الإثارة العاطفية مما يؤكّد ويرسّخ في ذهن المتلقي صفة الماضي ولئي

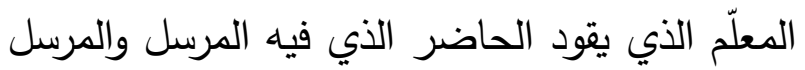
إليه؛ لأنّ ابن رجب الحنبلي في انجذابه للتراث يسير على قاعدة السلف والخلف، فالسلف طيب رجي صادق إن ابله
وترسم الإشاريّة ملامح مقصد المرسل المضمرة في

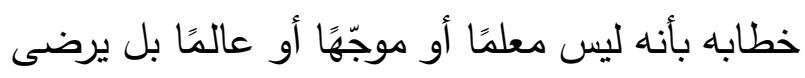

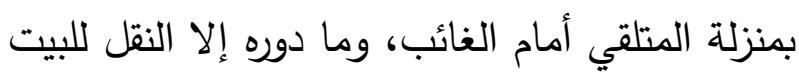

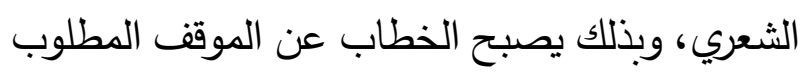
من الماضي، وهو أنْ يصبح الماضي معلمًا، والحاضر الذي يجمع المرسل والمرسل إليه تلميذًا للماضي. إنّ الإشارية للغائب يلمح فيها التضامن بين المرسل والمرسل إليه في الخطاب أمام المنشئ الحقيقي للملفوظ، ويكون ذلك عبر مستوى الحضور والغياب، فالحاضر متعلّم والماضي معلّم، والعلاقة في الخطاب

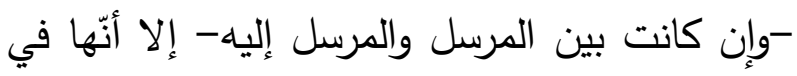

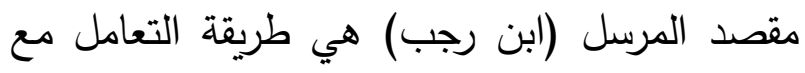
الماضي، وكيفية التلقي للمعرفة منه. وبما أنّ خطاب ابن رجب الحنبلي في توظيف البيت الشعري يجعل المرسل والمرسل إليه في تضامن أمام الماضي، وفي عمل موحّد في التلقي عبر الإشاريات للغائب إلا أنّ خطاب ابن رجب يتضدن موحن إشاريّة وحيدة للمتكلم عبر الضمير (نا) الذي يدلّ على الجمع. وهذه الإشارية تفهم من خلال المفارقة بين معناها الحرفي ومعناها التلميحي في الخطاب فقد قال ابن رجب الحنبلي في شرح الحديث الأربعين عَنِ ابْنِ عُمَرَ

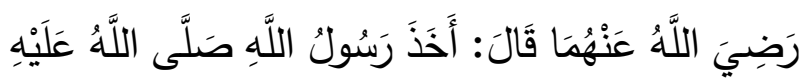

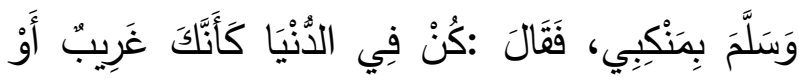


ابن رجب عندما يستعمل الإشاريّة (هذا) و(ذلك)، ويظهر منهما اختلاف المكان بين المتكلم ولفظ البيت الشعري.

وإذا كانت الإشارة بـ(هذا) تعني (هنا) لموقع المتكلم من الخطاب فإنّ البيت يحافظ على ماضيه من خلال مقابل موقع (هنا) المكاني وهو موقع (هنالك)؛ لأنّ الشعر يبقى في دائرة المكان المختلف عن مكان المتكلم الذي يضطلع بعملين: عمل إرسالي للخطاب، وعمل استقبالي له. ويظهر من الإشارية المكانية بـ(هذا) أنها تحدد المكان من أجل تحقيق وترسيخ الثّقابل بين الماضي والحاضر؛ لأنّ الخطاب حاضر المتكلّم والمتلقي، والبيت الشعري ماضي الخطاب والمتكلم والمتلقي، وهو هنا يتقّص دور السلف والخلف؛ لأنّ الحكمة في تلميحيّات ابن رجب الحنبلي سلفيّة، والعلوم في تلميحياته نبوية، وهذا هو سر جمعه بين العلم والحكمة في عنوان الكتاب. ومن الثواهد على ذلك من خطاب ابن رجب الحنبلي يقول فيه: " قال بعض الحكماء: من كانت الأيام والليالي مطاياه، سارت به وإن لم يسر ، وفي هذا قال بعضهم:

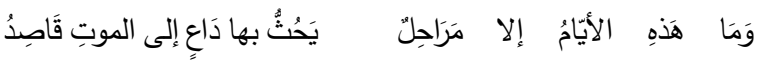

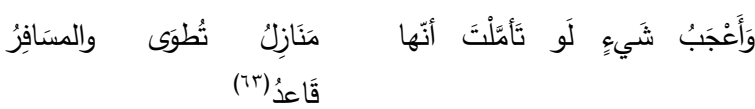

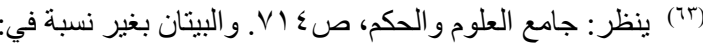

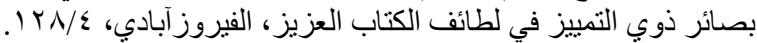

محظوظٌ بالقرب من زمن الرسالة النبوية، والخلف

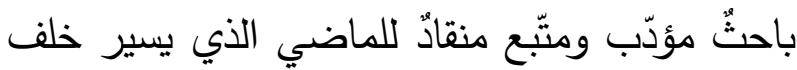
زمن الرسالة النبوية.

وتوظيف ابن رجب الحنبلي للبيت الشعري، والإشارة للمتكلم بضمير الجمع يدل على تناظر عالمين لديه: عالم الحاضر وعالم الماضي، وخطابه يتضمّن هذه الثائية التقابليّة؛ لأنه يريد اعتماد موقف من المتلقي، وإبقاء العلاقة مع الماضي متّصلا من خلال وضع نفسه مع المتلقي للخطاب ضمن ذات التكلّم التي يشير لها ضمير الجمع (نحن). ويظهر من الإشاريّات في خطاب ابن رجب الحنبلي إثاريّات مكانية تحيل على أماكن يعرفها المرسل إليه عبر كفاءته اللغويـة؛ ولأنّ المرسل لا ينفكّ عن المكان عند تلفظه بالخطاب(ال)، وفهم هذه العناصر الإشارية المكانية مرتبط بمعرفة مكان المتكلم، وموقعه أثناء إرسال الخطاب، ووعيه هو بمكانه من التّلفظ لغةً

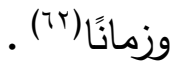
وتبرز في خطاب ابن رجب الحنبلي الإشارية للمكان (هذا) التي تشير إلى السابق على لفظ البيت الشعري؛ إذ يصبح الخطاب متضمنًا لمكانين: مكان المتكلّم وهو يرسل الخطاب، ومكان اللفظ بالنسبة لما سبقه من تلفّظات؛ لأنّ التداخل بين الشعر والنثر في الخطاب لا يعني تتازل الثعر عن خصائصها الثعرية ليصبح نثرًا، بل تبقى لله خصائصها الشعريـة التي يحافظ عليها 
وتعطي الإشاريّات للمكان مَسْرَحةً للأحداث بطريقة تلميحية؛ لأنّها تقوم بتقريب صورة الثخصيّات انطلاقًاً

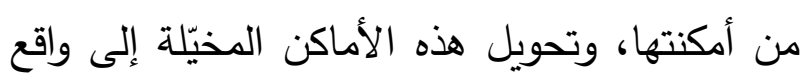

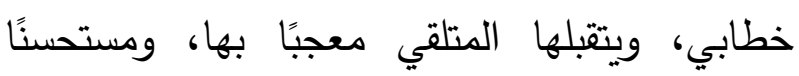
لطريقة عرضها (15) .

وينكثف مقصد من مقاصد الخطاب عند ابن رجب الحنبلي من خلال توظيفه للإثاريات المكانية؛ إذ معند

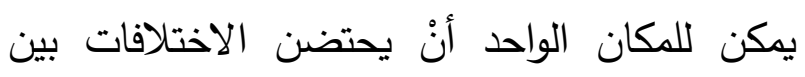
المتكلم والمخاطب ليتّددا في مقابل الغائب الذي يقع الذين في مكان (هناك) البعيد، وكلٌّ من المكان الخطابي الجامع بين المتكلم والمخاطب يقع في مقابل مكان الغائب، أي: يصبح المكان (هناك) أصلا يقاس عليه واقع المكان الذي يجمع بين أطراف الخطاب بشرط الفان

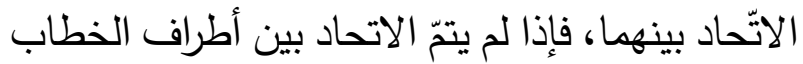

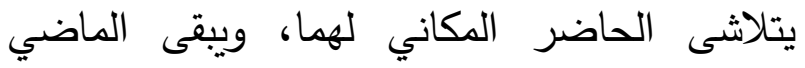
الككاني محتفظًا بشرط بقائه الذي يتمثّل في بقاء الغائب مستقلا به، ومستقرًا فيه. وتوجد في خطاب ابن رجب الحنبلي إثاريّات للزمان؛

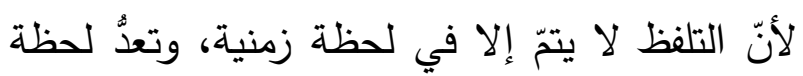
التّلفظ هي المرجع(10) ، ولابد لكل متلقي للخطاب أنْ يدرك اللحظة الزمانية التي نشأ فيها التلفظ فيتخذها مرجعًا يحيل عليه، ويؤول مكونات التلفظ اللغوية بناءا على معرفتها (T). وتتنوّع الأزمنة في خطاب ابن رجب الحنبلي بين أزمنة لفظها يخصّ الغائب، مثل: رأى في المنام، والليل)،
تأتي الإشارة بـ(هذا) للمعنى الموجود في قول

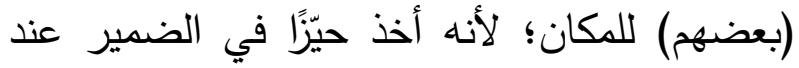
المتكلم والمخاطب، وكل شيء يشغل حيًّا يصبح حيّزه

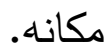
وفي إشارة ابن رجب الحنبلي بـ(هذا) يظهر أنه يشير

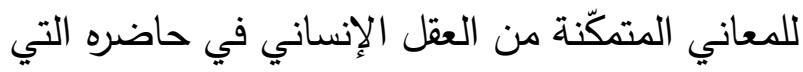
قد شغلت حيّزًا من ذهن المتلقي في زمن الخطاب، ثم الثي

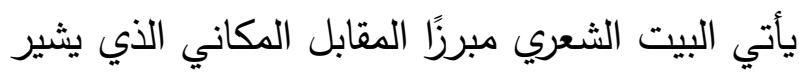

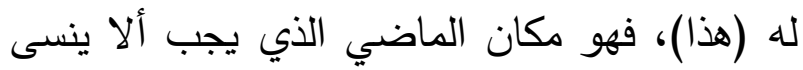
وألا يترك، بل يجب على المرسل والمرسل إليه التضامن في ذات واحدة تحتلّ مكانًا واحدًا يتميز به لهابه عالمها عن عالم البيت الشعري الذي هو ثابتُ في

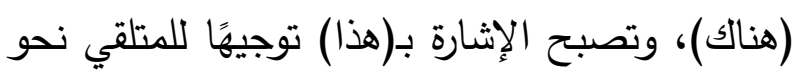
الجهة التي تشغلها المعاني وتلمّح إلى المكان البعيد الذي يجب أنْ يتوحّد المرسل والمرسل إليه من أجل ألهان التعرّف عليه، والاستفادة من إمكاناته. ثم إنّ توظيف الإشاريّات المكانية ومنها (هذا) تجمع المعاده بين مكان المتكلم والمخاطب فيصبحان في مكان واحد يمثّل (هنا)، ويقابلهما مكان البيت الشعري الذي يشير إلى الغائب (هو) ومكانه (هناك) الماضي، وتصبح قضيّة السلف والخلف حاضرة من خلال التّقابل بين مكان السلف الذي يمثله البيت الثعري في موقع من الثرن

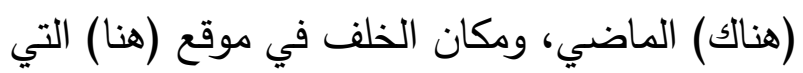

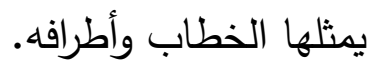


وتأتي الإشاريّات الزمانية ظاهرةً في الأفعال؛ لأنها تمكّن المتلقي من معرفة الفرق بين لحظة التلفظ بالخطاب ولحظة الملفوظ بالبيت الشعري، ومن ذلك لئك أنّ ابن رجب الحنبلي يستعمل الفعل (ينشد) في الثاهد التالي الذي قال فيه: " كلما قويت المعرفة صار الذكر لحئ يجري على لسان الذاكر من غير كلفة حتى كان بعضهم يجري على لسانه في منامه: الله الله، ولهذا يلهم أهل الجنّة التسبيح، كما يُلهمون النفس، وتصير

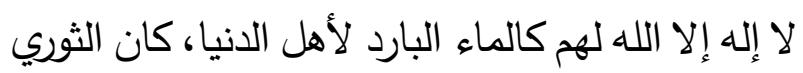

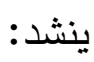

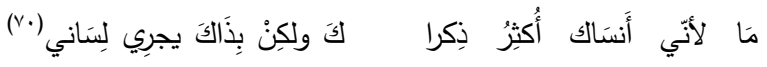
ويظهر من قوله: (كان ينشد) يدل على زمن الحاضر

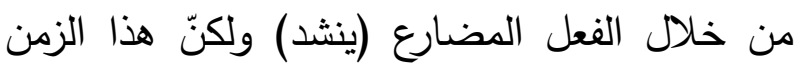

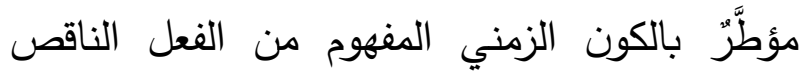

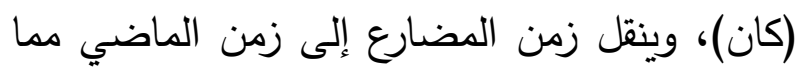

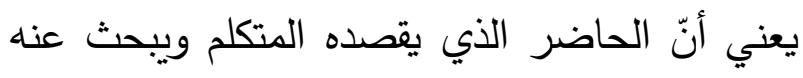

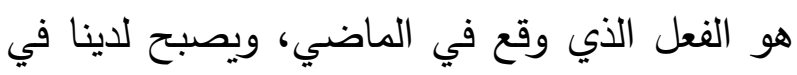

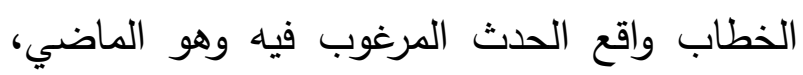
وواقع الخطاب الذي يجمع بين المتكلم والمخاطب أمام الماضي وهو واقع تأشيري، والواقع الثالث هو واقع لئع المتلقي للخطاب بعد اختقاء ابن رجب الحنبلي.

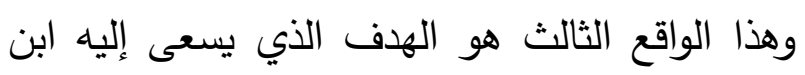

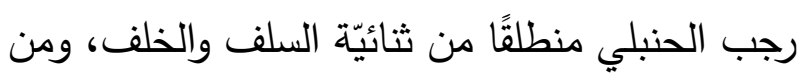

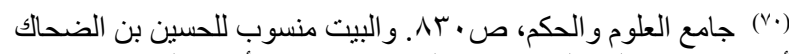

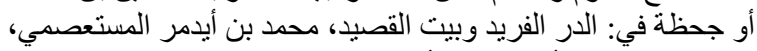

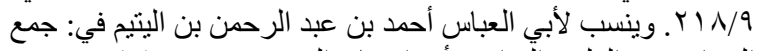

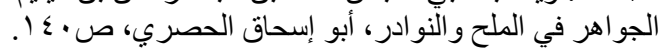

فهذه أزمنة تميّز لحظة التّلفظ في الخطاب عن لحظة الملفوظ الماضية، وهنا يتّحد زمن المتكلم والمخاطب

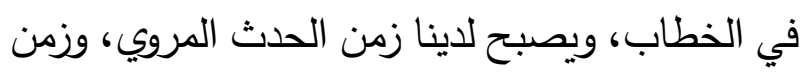
تلقي الحدث الموجود في البيت الشعري. إنّ ابن رجب الحنبلي في الإشاريّات الزمانية يصنع

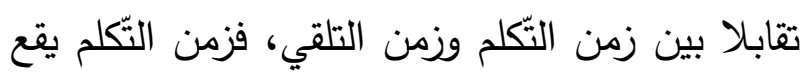

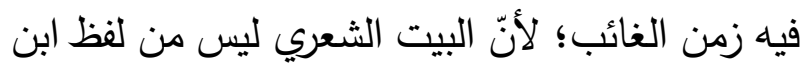

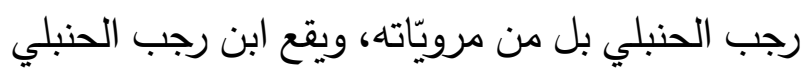
مع المرسل إليه في زمن التّلقي الذي يجمع بينهما.

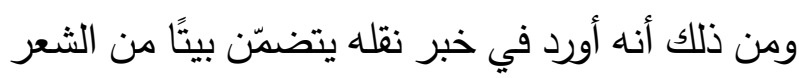
يقول: "وكانت رابعة قد فترت عن وردها بالليل مدّةً فأتاها آتٍ في منامها فأنشدها:

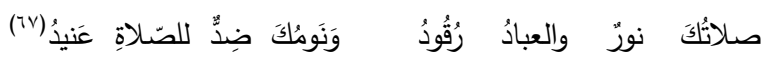
والإشارة هنا لليل الذي تضمن لحظة اللفظ في البيت الشعري؛ لأنّ "كل طبيعة لفظية تشير إلى زمن بعيد

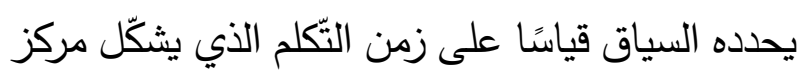

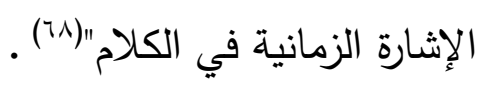
وتظهر فائدة الإشاريّات الزمانية عندما تتحد في ذهن الإنداري

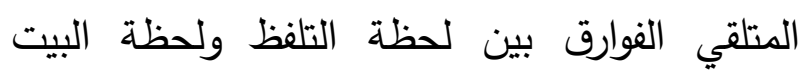
الشعري، وتقوم الإثاريات الزمانية بأمرين مهمين:

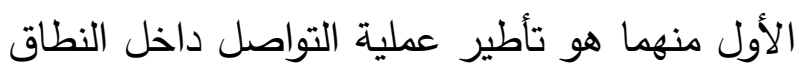

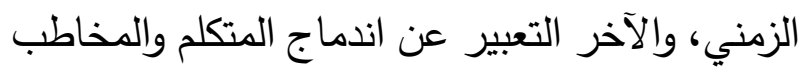
داخل الزمن النصّي والتلفظي والتواصلي(79). 
- - تقود ابن رجب الحنبلي فكرة السلف والخلف أثناء توظيف البيت الشعري مما جعل خطابه ينسجم مع انجذابه للتراث. - - مان الخطاب التلميحي إستراتيجية ابن رجب الحنبلي في تقريب المسافة بين الماضي والحاضر، ولذلك اهتمّ بعدم الإقناع بل بالتلميح والتأثير •

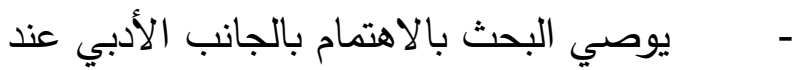
ابن رجب الحنبلي، من خلال دراسة الموضوعين التاليين:

(ا) الخبر الأدبي في كتاب جامع العلوم والحكم. (ب) شخصية ابن رجب الحنبلي الأدبية. وصلى الله وسلم على نبينا محمد، والحمد لله رب اله

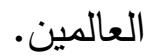

\section{المراجع}

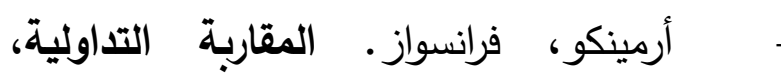
ترجمة: سعيد علوش، (الرباط: منشورات مركز الإنماء

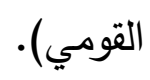

البستي، محمد بن حبان. روضة العقلاء ونزهة الفضلاء، تحقيق: محمد محيي الدين عبد الحميد، (بيروت: دار الكتب العلمية).

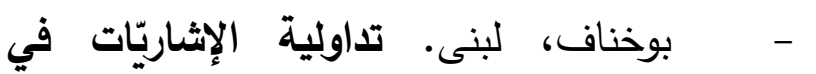
الخطاب الروائي لإبراهيم الكوني "رواية نزيف الحجر أنموذجًا"، مجلة روليات جامعة قالمة للعلوم الاجتماعية والإنسانية، عدد VY، ديسمبر 9 ا • rم.
رغبته في الإرشاد إلى أهمية الاتصال باللحظات الزمنية السالفة؛ لأنها اللحظة التي تمثّل انجذابه للتراث، واهتدائه بروايات الماضي من أجل مقاربة صحيحة لواقع الرسالة النبوية. الخاتمة التونة

انتهى البحث إلى النتائج التالية:

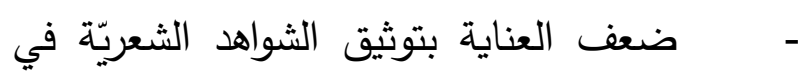
التحقيقات المتعددة التي اطلع عليها الباحث.

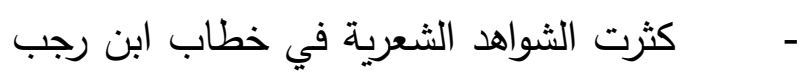
الحنبلي؛ لأنه ينحو نحو التعليم والتثقيف مما يجعله يميل إلى التلميح. - - كانت الشواهد الشعرية في موضوعين هما: الحب والزهد، مما يدل على النزعة التصوفيّة عند ابن رجب الحنبلي. - - اهتمام ابن رجب الحنبلي بالجمع بين التثقيف والمتعة من خلال المداخلة بين الثعر والنثر مما يدلّ على وعيه الأدبي.

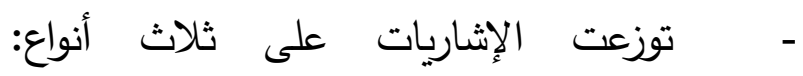
شخصية، ومكانية، وزمانية. - - اهتم ابن رجب الحنبلي باستراتيجية التضامن داخل الإستراتيجية التلميحية في خطابه ليصنع اتحادًا مع المتلقي، وهذا يدل على عاطفته التعليمية. - ركّز في الإشاريّات على أن تكون في مستويين: مستوى الحضور للمرسل والمرسل إليه، ومستوى الغياب لقائل البيت الشعري. 
الحصري، أبو إسحاق إبراهيم. جمع الجواهر في الملح والنوادر، تحقيق: علي محمد البجاوي،

$$
\text { (بيروت: دار الجيل، طץ). }
$$

ابن حنبل، أحمد. مسند الإمام أحمد بن حنبل، تحقيق: شعيب الأرناؤوط وآخرون، (بيروت:

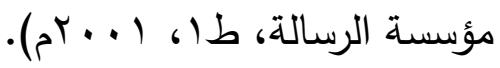

حمداوي، جميل. التداوليات وتحليل الخطاب،

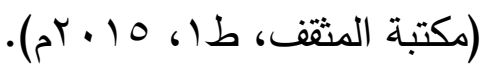

الخطيب التزويني. الإيضاح في علوم

$$
\text { البلاغة، (بيروت: دار الكتب العلمية). }
$$

- - - الخرازي، بديعة. مفهوم الثعر عند نقاد المغرب والأندلس في القرنين السابع والثامن الهجريين "دراسة نقدية تحليلية"، (المغرب: دار نشر

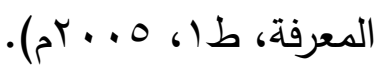

- - ابن الخطيب، لسان الدين. السحر والثعر، تحقيق: مفتاح محمد، رسالة علمية غير منشورة في

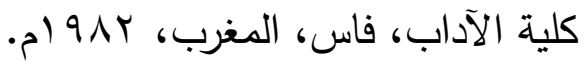

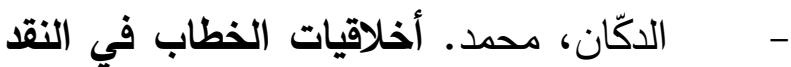
العربي القديم -عبد القاهر الجرجاني أنموذجًا-، مجلة العلوم العربية، جامعة الإمام محمد بن سعود

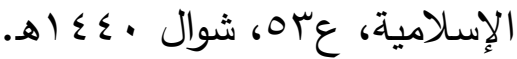
- مديوان أبي بكر الشبلي، تحقيق: د. دالهول كامل مصطفى الثيبي، (بغداد: المجمع العلمي العراقي، لئي،

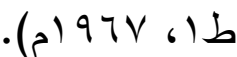
- - مالرازي، فخر الدين. مفاتيح الغيب، التفسير

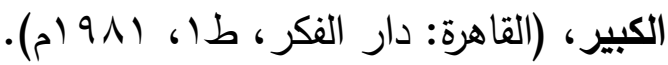

بوقرة، نعمان. لسانيات الخطاب مباحث في

التأسيس والإجراء، (بيروت: دار الكتب العلمية، طا، مباه $\cdot(4,+) r$

ابن بشران، أبو القاسم عبد الملك. أمالي ابن بثران، تحقيق: أحمد بن سليمان، (الرياض: دار الوطن للنشر، ط (، 999 (م). بولونوار، سعد. آليات تعليل الخطاب في تفسير أضواء البيان للثنقيطي "تحديد المفاهيم النظرية"، جامعة قاصدي مرباح ورقلة، كلية الآداب واللغات، 11 ـ ـ-r | • rم، رسالة دكتوراه. الثعالبي، أبو منصور · يتيمة الدهر في محاسن أهل العصر، شرح وتحقيق: مفيد قيحة، (بيروت، دار الكتب العلمية، طا، به19 (م). ابن رجب الحنبلي. جامع العلوم وإلكم في شرح خمسين حديثا من جوامع الكلم، تحقيق: طارق بن عوض الله، (الرياض: دار ابن الجوزي، طء؛ . (ه) $\leqslant r r$ - - - ابن الجوزي، عبد الرحمن. المدهش، تحقيق: مروان قباني، (بيروت: دار الكتب العلمية، طץ، .00000 - - - ابن الجوزي، عبد الله. المنامات، تحقيق: عبد القادر أحمد عطا، (بيروت: مؤسسة الكتب الثقافية، . ط) الجوهري، إسماعيل بن حماد. الصحاح تاج اللغة وصحاح العربية، تحقيق: أحمد عبد الغفور

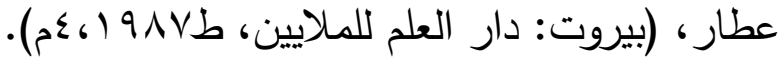




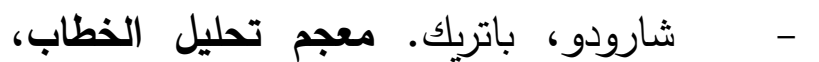
بإشراف: باتريك ودومينيك منغو، ترجمة: عبد القادر

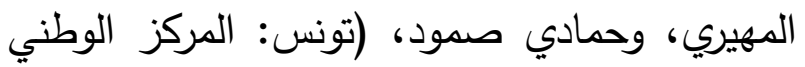

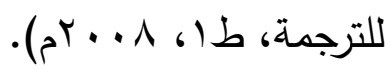

الشهري، عبد الهادي. استراتيجيات الخطاب

"مقاربة لغوية تداولية"، (بيروت: دار الكتاب الجديد

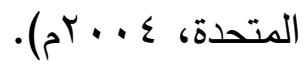

- - مبلينر ، لبراند. علم اللغة والدراسات الأدبية، ترجمة: محمود جاب الرب، (القاهرة: الدار الفنية

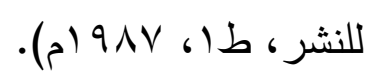

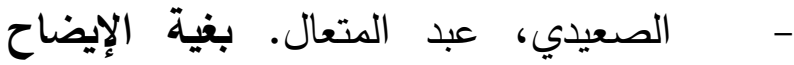
لتلخيص المفتاح في علوم البلاغة، (القاهرة: مكتبة

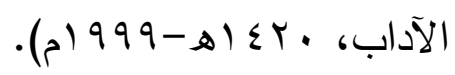
طبانة، بدوي. معجم البلاغة العربية، طس،

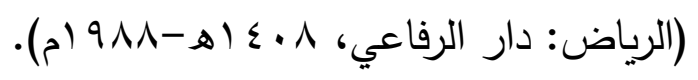

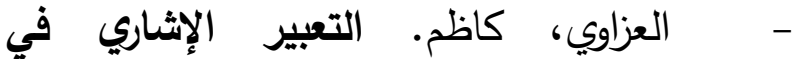
الخصيبي "مقاربة تداولية"، مجلة جامعة بابل، مجلد

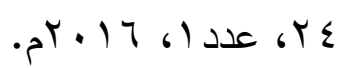

- - - العثيمين، محمد بن صالح. التعليق على ميمية ابن القيم، (القصيم: مؤسسة الشيخ محمد بن مين

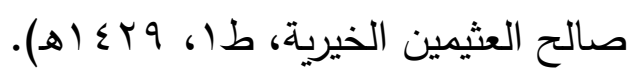

- - مابن فارس، أحمد. معجم مقاييس اللغة،

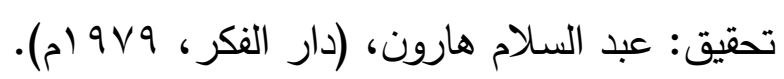

- - متحي، إبراهيم. معجم المصطلحات الأدبية، (تونس: المؤسسة العربية للناشرين المتحدين،
- - مارازي، محمد. مختار الصحاح، (بيروت: مكتبة لبنان، 919 (م).

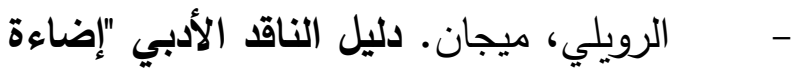
لأكثر من سبعين تيارًا ومصطلحًا نقديًا معاصرًا"، ميجان الرويلي وسعد البازعي، (الدار البيضاء،

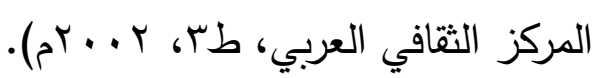
الزبيدي، مرتضى محمد. تاج العروس من جواهر القاموس، دار الهداية.

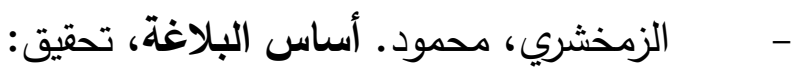
محمد باسل عيون السود، (بيروت: دار الكتب العلمية،

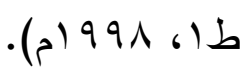
الزمشري، محمود. الكشاف عن حقائق غوامض التنزيل وعيون الأقاويل في وجوه التأويل، ضبط: أبي عبد الله الداني، (بيروت: دار الكتاب

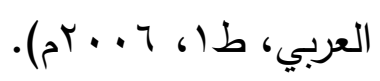

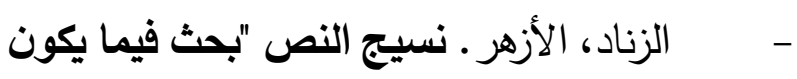
به الملفوظ نصَّا"، (بيروت: المركز الثقافي العربي،

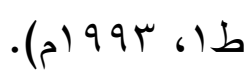
السجلماسي، أبو محمد. المنزع الببيع في

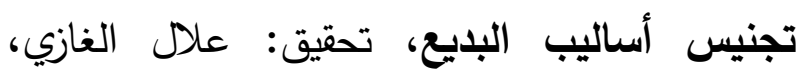
(الرباط: مكتبة المعارف، طان، لـ191 (19).

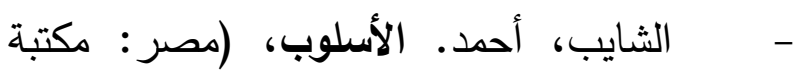
النهضة المصرية، طץ (، ب. . بم).

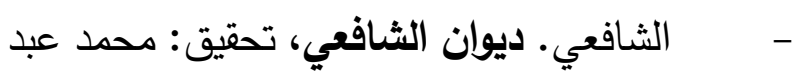

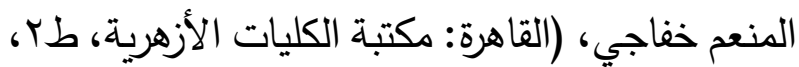
. (a) 910 
هتولي، عبد الستار السيد. أدب الزهد في العصر العباسي "نثأته وتطوره وأثهر رجاله"، (رسالة دكتوراه في مكتبة جامعة أم القرى، بV و (م)). - - - المتنبي، أبو الطيب. ديوان أبي الطيب المتنبي بشرح أبي البقاء العكبري، تحقيق: مصطفى الب لئي السقا وآخرون، (مصر ، مطبعة مصطفى البابي الحلبي). - - المستعصمي، محمد. الار الفريد وبيت القصيد، تحقيق: كامل الجبوري (بيروت: دار الكتب

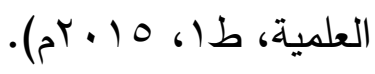

- - - ابن المقرئ، محمد. معجم ابن المقرئ،

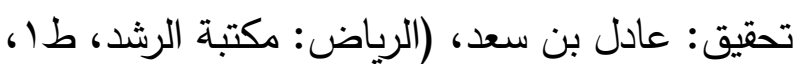
. (م) 991 بن منظور ، محمد. لسان العرب، (بيروت:

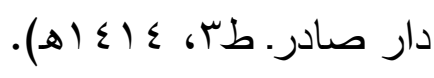
نحلة، محمود. آفاق جديدة في البحث اللغوي المعاصر، (الإسكندرية: دار المعرفة الجامعية، ،

$$
\cdot(r) r
$$

يول، جورج. التداولية، ترجمة: قصي

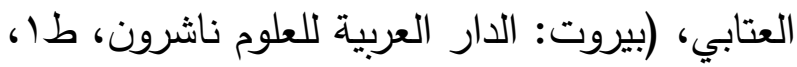
$\left.\cdot()^{3} \cdot\right) \cdot$

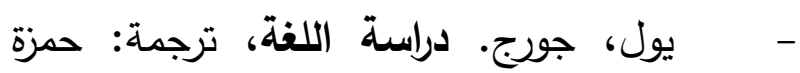

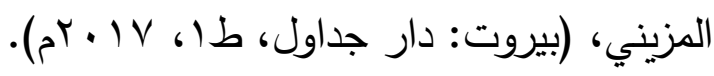

الفراهيدي، الخليل بن أحمد. العين، تحقيق: مهدي المخزومي وإبراهيم السامرائي، (دار ومكتب (الهلال). فوكو، ميشيل. حفريات المعرفة، ترجمة: سالم

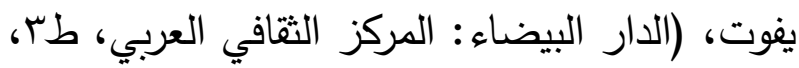
.$(5, \cdot 0$

الفيروزآبادي، محمد. بصائر ذوي التمييز في

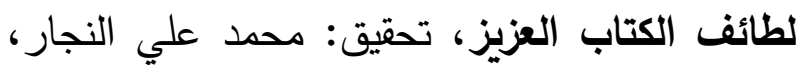

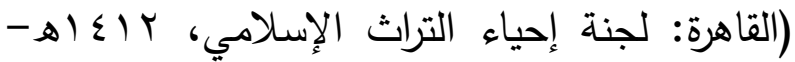
.$(5) 994$

الفيروزآبادي، محمد. القاموس المحيط "مرتب ترتيبا ألفبائيا وفق أوائل الحروف"، راجعه: أنس الثامي وزكريا جابر، (القاهرة: دار الحديث،

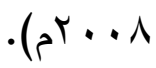
القرطاجني، حازم. منهاج البلغاء وسراج

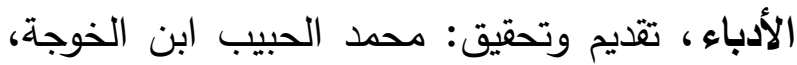

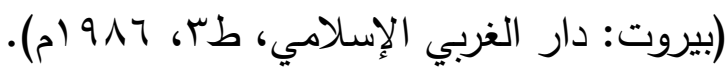

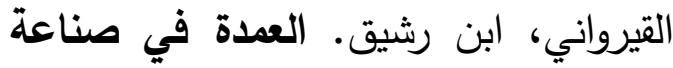
الثعر ونقده، تحقيق: النبوي عبد الواحد شعلان، آنيق، (القاهرة: مكتبة الخانجي، طا، . . . rم). الكرماني، محمد بن يوسف. تحقيق الفوائد الغياثية، تحقيق: علي بن دخيل الله العوفي، (المدينة: مكتبة العلوم والحكم، طا، ـr ع (ه). 


\section{المراجع الانجليزية}

- Armenko, Francoise. The deliberative approach, translated by: Said Alloush, (Rabat:

National Development Center Publications). - Al-Basti, Mohammed bin Habban. Rawdat Al-Aqla and Nozha Al-Fadla, edited by: Muhammad Mohiuddin Abdel-Hamid, (Beirut:

(Dar Al-Kutub Al-Ilmiyya). - Bukhnaf, Lubna. The Circular of Allegations in Ibrahim Al-Koni's fictional discourse "The Bleeding of the Stone as a Model", Annals of Guelma University for Social Sciences and Humanities, Issue 27, December 2019. - Bougherra, Naaman. The linguistics of the discourse, a discussion of establishment and procedure, (Beirut: Dar Al-Kotob Al-Ilmiyya,

(1st Edition, 2012 AD).

- Ibn Bishran, Abu al-Qasim Abdul-Malik. Amali Ibn Bishran, Edited by: Ahmed bin Suleiman,(Riyadh: Dar Al-Watan Publishing, (1st Edition, 1999 AD)

- Polonnwar, Saad. Mechanisms of Discourse Analysis in Interpreting Adwaa Al-Bayan by Al-Shanqeeti "Defining Theoretical Concepts", Qasidi Merbah and Ouargla University, Faculty of Arts and Languages, 2011-2012 AD, PhD thesis.

- Al-Thaalabi, Abu Mansour. Yateematuldahr, investigated by: Mufid Qumaiha, (Beirut, Dar (Al-Kutub Al-Ilmiyya, 1st Edition, 1983 AD). - Ibn Rajab Al-Hanbali. Jami` al-Ulum wa alHukm in Explaining Fifty Hadiths of Jami alKalam, edited by Tariq Ibn Awad Allah, (Riyadh: Dar Ibn Al-Jawzi, 4th Edition, 1423

(AH).

- Ibn Al-Jawzi, Abdul-Rahman. Al-Modhesh, edited by: Marwan Qabbani,(Beirut: Dar Al-
Kutub Al-Ilmiyya, 2nd Edition, 1405 AH-

- Ibn Al-Jawzi, Abdullah. Al-Manamat, edited by: Abd al-Qadir Ahmad Atta, (Beirut: Cultural (Books Foundation, 1st Edition, 1993 AD). - Al-Gohary, Ismail bin Hammad. As-Sahhah Taj Alugah and Sahhah Al-Arabiya, edited by: Ahmad Abd Al-Ghafoor Attar, (Beirut: Dar AlAlam Al-Malayyeen, 4th Edition, 1987 AD). - Al-Hosari, Abu Ishaq Ibrahim. Jamea Aljawaher, edited by: Ali Muhammad AlBajawi, (Beirut: Dar Al-Jeel, 2nd ed.) - Ibn Hanbal, Ahmad. Musnad of Imam Ahmad bin Hanbal, edited by: Shuaib Al-Arna`out and others, (Beirut: Foundation for the Resalah, 1st

Edition, 2001 AD).

- Hamdaoui, beautiful. "Altdawlyat wa thleel Alkhitab", (Al-Muhtafif Library, 1st Edition,

2015 AD).

- Khatib Qazwini." Aleydah fi alum Albalagah", (Beirut: Dar Al-Kutub Al-'Ilma). - Al-Kharazi, Badi'a. The concept of poetry among the critics of Morocco and Andalusia in the seventh and eighth centuries $\mathrm{AH}$, "An Analytical Critical Study", (Morocco: Knowledge Publishing House, 1st Edition, 2005 AD). - Ibn al-Khatib, Lisan al-Din. Alsihr wa Alshi'r, edited by: Miftah Muhammad, an unpublished scientific thesis in the Faculty of Arts, Fez,

Morocco, 1982 AD).

Aldukan, Muhammad. The Ethics of Discourse in Ancient Arab Criticism - Abd al-Qaher alJarjani as an example-, Journal of Arab Sciences, Imam Muhammad Ibn Saud Islamic University, Vol.53, Shawwal 1440 AH. - Abi Bakr Al-Shibli Diwan, edited by: Dr. Kamel Mustafa al-Shaibi,(Baghdad: The Iraqi (Scientific Complex, 1st Edition, 1967 AD) 
- Al-Razi, Fakhreddin. "Mafateeh Algyb" (Keys to the Unseen), Al-Tafsir Al-Kabeer,

(Cairo: Dar Al-Fikr, 1st Edition, 1981 AD.

- Al-Razi, Muhammad. Mukhtar As-Sahah,

(Beirut: Lebanon Library, 1986.

- Al-Ruwaili, Megan. The Literary Critic's Handbook "Illumination of More than Seventy Current Critical Current and Contemporary Critical Terms" by Megan Al-Rouaili and Saad Al-Bazai (Casablanca, Arab Cultural Center, 3rd Edition, 2002 AD).

- Al-Zubaidi, Mortada Muhammad. Taj alarous, Dar Al-Hidaya.

- Zamakhshari, Mahmoud. Asas Albalagah, edited by: Muhammad Basil Oyoun Al-Soud, (Beirut: Dar Al-Kotob Al-Alami, Edition 1, 1998 AD..

- Zamakhshari, Mahmoud. Alkashaf, edited by: Abi Abdullah Al-Dany, (Beirut: Dar Al-Kitab Al-Arabi, Edition 1, 2006 AD). - Alzinad, Al-Azhar. Naseej Alnus "A Study of What the Spoken Is Text" (Beirut: The Arab Cultural Center, 1st Edition, 1993 AD). - Al-Sijilmasi, Abu Muhammad. Al-Manza AlBadi'i, edited by Allal Al-Ghazi, (Rabat: Library of Knowledge, Edition 1, 1980). - Al-Shayeb, Ahmed. The Style, (Egypt: The Egyptian Renaissance Library, 12th Edition, 2003 AD).

- Shafi'i. The Shafi'i Diwan, edited by: Muhammad Abdel Moneim Khafagy, (Cairo: Al-Azhar Colleges Library, 2nd Edition, 1985

$\mathrm{AD})$.

- Sharodoo, Patrick. Dictionary of Discourse Analysis, supervised by: Patrick and Dominique Mengo, translated by: Abdelkader El Mehairi and Hammadi Samoud, (Tunisia: National Center for Translation, 1st Edition,
- Al-Shehri, Abdul Hadi. Discourse Strategies, "A Linguistic Interdisciplinary Approach", (Beirut: The New Book United House, 2004. - Chipliner, Lybrand. Linguistics and Literary Studies, translated by: Mahmoud Jab El-Rab, (Cairo: Technical Publishing House, 1st Edition, 1987 AD.

- Al-Saidi, Abdel Mutaal.Bagyat Aleydah, (Cairo: Library of Arts, 1420 AH -1999 AD).

- Tabbana, Badawi. Dictionary of Arabic Rhetoric, 3rd Edition, (Riyadh: Dar Al-Rifai 1408 AH -1988 AD).

- Al-Azzawi, Kazem. Signal Expression in AlKhasibi, "Contemplative Approach", Babylon University Journal, Volume 24, Issue 1, 2016 AD. - Al-Uthaymeen, Muhammad bin Saleh. Commentary on the memorial of Ibn alQayyim, (Al-Qassim: Sheikh Muhammad Bin Saleh Al-Uthaimin Charitable Foundation, 1st Edition, 1429 A.H. - Ibn Faris, Ahmad. Dictionary of Language Standards, edited by: Abd al-Salam Haroun, (Dar al-Fikr, 1979. - Fathy, Ibrahim. Dictionary of Literary Terms (Tunisia: Arab United Publishers Foundation, 1986). - Al-Farahidi, Al-Khalil bin Ahmed. Al-Ain, edited by: Mahdi Al-Makhzoumi and Ibrahim Al-Samarrai, (Al-Hilal House and Office). - Foucault, Michel. Knowledge Excavations, translated by Salem Yefout, (Casablanca: Arab Cultural Center, 3rd Edition, 2005 AD). - Al-Fayrouzabadi, Muhammad." Bsaer thwy altmyuth", edited by: Muhammad Ali AlNajjar, (Cairo: Committee for the Revival of Islamic Heritage, 1412 AH -1992 AD). 2008 AD). 
- Al-Fayrouzabadi, Muhammad. Alqamous almuheet, "arranged alphabetically according to the earliest letters," revised by: Anas Al-Shami and Zakaria Jaber, (Cairo: Dar Al-Hadith, 2008

AD).

- Carthagni, Hzim. Manhaj al-Bulagha and Siraj al-Adaba ', presented and investigated by: Muhammad Al-Habib Ibn Al-Khawja, (Beirut: Dar Al-Gharbi Al-Islami, 3rd Edition, 1986

$\mathrm{AD})$.

- Al-Qayrawani, bin of Rashiq Al-Umda ,"Sinaat Alshir wa naqdah", edited by: AlNabawi Abd Al-Wahid Shaalan, (Cairo: AlKhanji Library, 1st Edition, 2000 AD). - Al-Kirmani, Muhammad bin Yusuf. Tahqeq Alfwaed Al-Ghayathia, edited by Ali bin Dakheel Allah Al-Awfi, (Al-Madinah: Science and Governance Library, 1st Edition, 1424

A.H).

- Metwally, Abdul Sattar. Literature of asceticism in the Abbasid era, "its origin, development, and most famous men", (PhD thesis in Umm Al-Qura University Library, 1972 AD).
- Al-Mutanabi, Abu Al-Tayeb. The Diwan of Abi Al-Tayyeb Al-Mutanabi, with the explanation of Abi Al-Baqa Al-Akbari, edited by: Mustafa Al-Sakka and others, (Egypt, Mustafa Al-Babi Al-Halabi Press. - Al-Mustasmi, Muhammad. Al-Durr Al-Farid wa Bayt Al-Qaseed, edited by: Kamel AlJubouri (Beirut: Dar Al-Kotob Al-Ilmiyya, 1st Edition, 2015). - Ibn Al-Muqir, Muhammad. Mujam Ibn AlMuqri, edited by: Adel bin Saad, (Riyadh: AlRashed Library, 1st Edition, 1998 AD. - Ibn Manzur, Muhammad. Lisan Al Arab (Beirut: Dar Sader 3rd Edition, 1414 A.H). - Nahlah, Mahmoud. New Horizons in Contemporary Linguistic Research, (Alexandria: University Knowledge House, 2002 AD).

- Yule, George. The deliberative, translated: Qusay Al-Attabi, (Beirut: Arab Science Publishers, 1st Edition, 2010 AD). - Yule, George. Language study, translated by Hamza Al-Muzaini, (Beirut: Dar Jadal, 1st Edition, 2017 AD. 
عوض بن إبراهيم بن خليف العنزي

\title{
The suggestive discourse in the poetic verse of Ibn Rajab Al-Hanbali The Book of " Jami` Al-Ulum wa Al-Hukm " as a Model
}

\author{
Dr. Awad bin Ibrahim bin Khalif Al-Anzi \\ Assistant Professor in the Department of General Subjects \\ Faculty of Science and Arts in Rafha - Northern Border University
}

\begin{abstract}
. the importance of the poetic verse emerges when it is used in other than its meanings and from those meanings are books explaining the prophetic hadith. As it comes to use it to serve the prophetic text, and to enable its meanings for the recipients.

Among those scholars who have emerged to use the poetic verse in its commentaries is the Imam Al-Hafiz Abdurahman bin Ahmad Al-Salami, who famous for Ibn Rajab al-Hanbali, born in Baghdad in the year $736 \mathrm{AH}$ and died in the year $795 \mathrm{AH}$.

The use of the poetic verse in the narrative discourse feels that it is not devoid of a function that serves the shrine, doubles its achievement power, and reveals hints of the sender in his using in which he is united with the addressee.

Due to the nature of the collection of poetic scientific material, the research is divided into: an introduction, two chapters, a conclusion, and references that contributed to
\end{abstract}

Keywords: Deliberative, indications, using, discourse strategies 